University of Nebraska - Lincoln

DigitalCommons@University of Nebraska - Lincoln

Publications from USDA-ARS / UNL Faculty

U.S. Department of Agriculture: Agricultural

Research Service, Lincoln, Nebraska

2014

Biology and Management of Psocids Infesting Stored Products

\author{
Manoj K. Nayak \\ Department of Agriculture, Australia, manoj.nayak@daff.qld.gov.au \\ Patrick J. Collins \\ Plant Biosecurity Cooperative Research Centre, pat.collins@daff.qld.gov.au \\ James E. Throne \\ USDA-ARS, Manhattan, KS, james.throne@ars.usda.gov \\ Jin-Jun Wang \\ Southwest University, China, wangjinjun@swu.edu.cn
}

Follow this and additional works at: https://digitalcommons.unl.edu/usdaarsfacpub

Nayak, Manoj K.; Collins, Patrick J.; Throne, James E.; and Wang, Jin-Jun, "Biology and Management of Psocids Infesting Stored Products" (2014). Publications from USDA-ARS / UNL Faculty. 1988.

https://digitalcommons.unl.edu/usdaarsfacpub/1988

This Article is brought to you for free and open access by the U.S. Department of Agriculture: Agricultural Research Service, Lincoln, Nebraska at DigitalCommons@University of Nebraska - Lincoln. It has been accepted for inclusion in Publications from USDA-ARS / UNL Faculty by an authorized administrator of DigitalCommons@University of Nebraska - Lincoln. 


\title{
Biology and Management of Psocids Infesting Stored Products
}

\author{
Manoj K. Nayak, ${ }^{1,2, *}$ Patrick J. Collins, ${ }^{1,2}$ \\ James E. Throne, ${ }^{3}$ and Jin-Jun Wang ${ }^{4}$
}

${ }^{1}$ Department of Agriculture, Fisheries and Forestry, Ecosciences Precinct, Brisbane, QLD 4001, Australia; email: manoj.nayak@daff.qld.gov.au,pat.collins@daff.qld.gov.au

${ }^{2}$ Plant Biosecurity Cooperative Research Centre, Bruce, ACT 2617, Australia

${ }^{3}$ USDA, Agricultural Research Service, San Joaquin Valley Agricultural Sciences Center, Parlier, California 93648-9757; email: James.Throne@ars.usda.gov

${ }^{4}$ College of Plant Protection, Southwest University, Chongqing 400716, P.R. China; email: wangjinjun@swu.edu.cn

Annu. Rev. Entomol. 2014. 59:279-97

First published online as a Review in Advance on October 18, 2013

The Annual Review of Entomology is online at ento.annualreviews.org

This article's doi:

10.1146/annurev-ento-011613-161947

Copyright (c) 2014 by Annual Reviews. All rights reserved

${ }^{*}$ Corresponding author

\section{Keywords}

control, ecology, Liposcelididae, population growth, Psocoptera

\section{Abstract}

Previously regarded as minor nuisance pests, psocids belonging to the genus Liposcelis now pose a major problem for the effective protection of stored products worldwide. Here we examine the apparent biological and operational reasons behind this phenomenon and why conventional pest management seems to be failing. We investigate what is known about the biology, behavior, and population dynamics of major pest species to ascertain their strengths, and perhaps find weaknesses, as a basis for a rational pest management strategy. We outline the contribution of molecular techniques to clarifying species identification and understanding genetic diversity. We discuss progress in sampling and trapping and our comprehension of spatial distribution of these pests as a foundation for developing management strategies. The effectiveness of various chemical treatments and the availability and potential of nonchemical control methods are critically examined. Finally, we identify research gaps and suggest future directions for research. 


\section{INTRODUCTION}

Stored products: include raw and processed foods, foodstuffs, and durable items, and materials such as timber and museum artifacts
Relegated to the category of minor pests, along with other incidental invaders such as silverfish and cockroaches, psocids have mostly been ignored by entomologists who were preoccupied with combating the ravages of the larger, more prominent and more destructive beetle and moth pests of stored commodities (79). Generally associated with moist conditions, psocids were dismissed as incidental mold feeders (99), present as a result of poor storage practice, inflicting negligible or no damage to the commodity. More broadly, psocids were best known as nuisance pests, often encountered in books and stacks of papers (from which they derive the common name booklice), or as pantry pests $(99,100)$. They have received only superficial or passing mention even in the most recent texts on stored-product protection (30).

The pest status of psocids began to change internationally in the late 1980s as the first reports of large infestations rapidly establishing in stored grains emerged from West Africa and Southeast Asia (81). These accounts were followed by reports of heavy infestations in stored grains in Indonesia $(38,92)$, India (84), China (108), and Australia (85, 64). Severe infestations have also been reported from such diverse locations as food-processing facilities and feed and flour mills in Italy (97) and the United States (3, 71), tobacco-processing houses in Zimbabwe (48), museums and bakeries in Czechoslovakia (68), and railroad cars used for transporting grain in Canada (94).

Pest management treatments and practices, aimed primarily at the major beetle pests, were clearly failing against psocids. The challenge for entomologists was to discover why these treatments were apparently suddenly failing and to determine the best approach to manage these pests. To do this, we needed a much greater understanding of the insects themselves and of their biological and ecological interactions with the stored commodity environment. Initial investigation determined that several species were responsible for control failures and that these belonged to the genus Liposcelis (Liposcelididae: Psocoptera) (46). However, information on the biology and ecology of these insects that could be used to support a rational pest management strategy was sparse.

In this review we describe progress of international efforts to develop our understanding and management of Liposcelis psocid pests. We synthesize the significant experimental data and explain how this information has framed our comprehension of these insects and how it has informed pest management strategies.

\section{IDENTIFICATION AND KEY CHARACTERISTICS}

\section{Identification}

Psocids belonging to the genus Liposcelis are small (about $1.0 \mathrm{~mm}$ ), wingless, soft-bodied, brown to creamy yellow in color, and active insects with large heads and protruding eyes (Figure 1 $\boldsymbol{a}, \boldsymbol{b})$. Approximately 100 species have been reported to infest stored products (46), 4 of which are economically significant worldwide: Liposcelis bostrychophila Badonnel, L. decolor (Pearman), L. entomophila (Enderlein), and L. paeta Pearman. Other pests of regional importance include L. corrodens Heymons, L. brunnea Motschulsky, and L. rufa Broadhead.

Infestations of more than one species are often encountered $(66,18)$, and because species have differing ecologies and therefore may vary in their responses to pest management actions, accurate and timely identification is vital. Morphological keys are available for identifying adults (55), but most species are difficult to recognize using traditional methods and require special expertise. Molecular methods offer a precise identification of species that is not limited to adults. Both the mitochondrial cytochrome $c$ oxidase I (COI) gene (33) and the ribosomal internal transcribed spacer (ITS) region (116) are used successfully to identify insect species-a technique known as barcoding. Some progress has been made in developing a molecular species identification kit for 

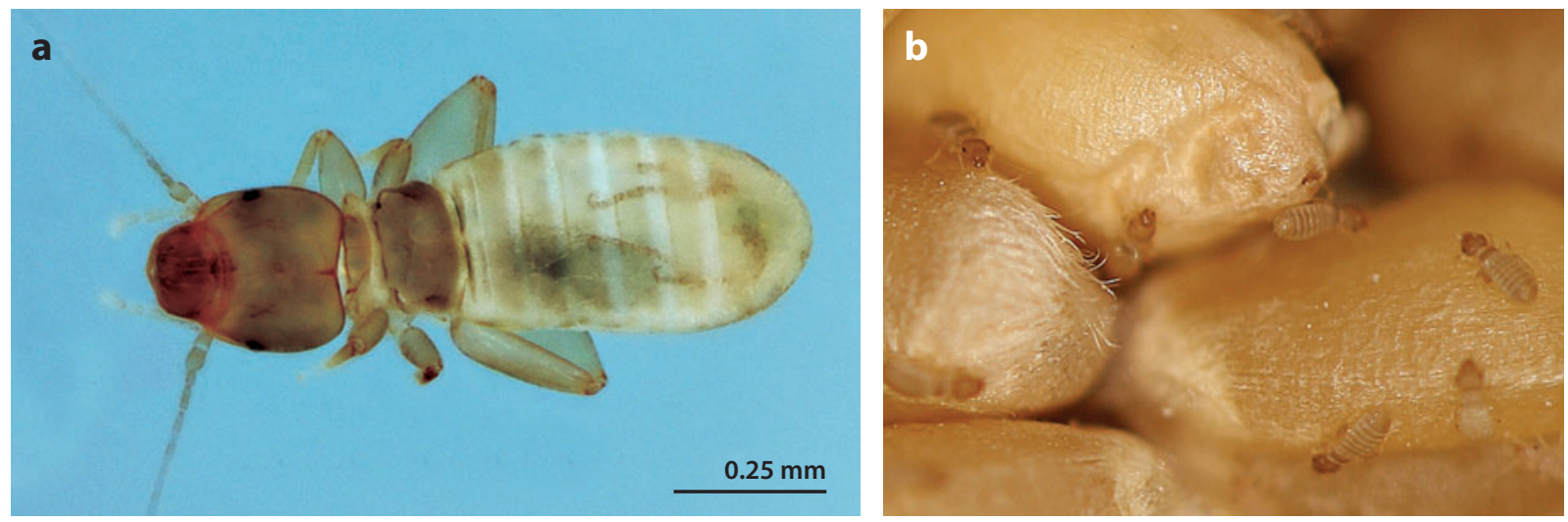

Figure 1

(a) A microscopic view of Liposcelis bostrychophila. (b) Liposcelis bostrychophila on wheat. Photos courtesy of Manoj K. Nayak, Department of Agriculture, Fisheries and Forestry, Queensland, Australia.

psocids. A multiplex PCR method based on ITS2 sequences was used for rapid identification of six psocid species, and this is an easier and more reliable method that could be widely applicable (112). Recently, 16S rDNA sequences and the COI gene were used to successfully differentiate eight common species of Liposcelis; the identifications were verified by morphological examination $(83,115)$.

\section{Key Characteristics}

Contrary popular belief, Liposcelis psocids are not just mold grazers. Numerous reports indicate that they can live on virtually any kind of food material of animal or plant origin so long as the moisture content or ambient relative humidity $(\mathrm{RH})$ is favorable $(\sim 70-80 \% \mathrm{RH})(39)$. Furthermore, experimental evidence has demonstrated that psocids can survive and even thrive on a diet of broken wheat grains in conditions not conducive to mold growth $(<70 \% \mathrm{RH})(87)$. An attribute crucial to the survival of these insects is their ability to actively absorb water from the atmosphere (39). Other important characteristics include their small size, which gives them the ability to exploit cracks and crevices and to remain concealed and unnoticed; short development period (23 weeks at $30-35^{\circ} \mathrm{C}$ and $75 \% \mathrm{RH}$ ) (Supplemental Table 1; follow the Supplemental Material link from the Annual Reviews home page at http://www.annualreviews.org), long adult stage (Supplemental Table 6); and the ability to survive adverse conditions, such as a lack of food, for relatively long periods (102). Furthermore, some species are predominantly parthenogenic, with all eggs developing into females, enabling a rapid increase in population (46).

The combination of these key factors enables Liposcelis species, particularly L. bostrychophila, L. entomophila, L. decolor, and L. paeta, to successfully colonize and then repeatedly reinfest stored commodities even when control treatments are applied. Access to moisture either from the commodity itself or from the atmosphere is crucial. A small, unnoticed residual population can explode to unmanageable proportions with a sudden increase in ambient humidity ( $>70 \%$ ) during monsoon periods or an increase in moisture content $(>13 \%)$ of the stored product in any storage environment. In heavy infestations, populations of 1,500 to 4,000 live psocids per kilogram of grain have been recorded (44). This phenomenon of repeated reinfestation by psocids has been documented from bulk wheat, sorghum, and barley storages (64) and from processed food warehouses (18) in warm temperate regions of Australia, and in bagged paddy rice, wheat, sorghum, 
Pesticide resistance: a heritable decrease in susceptibility of a pest to a pesticide that was previously effective at controlling the pest cassava, and animal feed stored in warehouses in the humid tropics of China $(17,108)$, India $(84)$, and Indonesia $(38,92)$.

\section{ECONOMIC IMPACT}

\section{Why Are They A Pest Now?}

The relatively sudden increase in the pest status of psocids appears to be linked to changes or improvements in the management of the major coleopteran pests of stored products. Field trials in Indonesia (82) indicated that psocid populations tended to flourish after the grain was treated with the pyrethroid insecticide permethrin, suggesting that the insects had a higher tolerance to the insecticide and that they benefited from the reduction of predators and competitors. This conclusion is supported by experiments performed in Australia demonstrating that psocid populations recover much more rapidly from poorly applied phosphine fumigations than beetle pests do, and that the red flour beetle Tribolium castaneum (Herbst) could markedly suppress L. paeta and L. entomophila populations through predation (91). The higher tolerance to insecticides has been confirmed in extensive work testing a range of materials $(5,19,21,60,62,64-66)$, although the response to chemicals by these insects is complex and varies across species (see below). It was suggested that increasing frequency and severity of psocid infestations in Australia were linked to the industry transitioning from broad use of contact insecticides to reliance on the fumigant phosphine (85), particularly the introduction of technology that allowed a continuous delivery of phosphine gas at relatively low concentrations through grain in open-top silos. Other factors include the relatively long period spent as eggs, which is the stage most tolerant to phosphine (63), and the development of pesticide resistance in several species $(59,80,84)$. The development of phosphine resistance and the greater tolerance of eggs to phosphine may explain the surge of control failures in countries in South and Southeast Asia. Many of these countries are developing export markets and are increasing their use of phosphine to meet international requirements for insect-free produce.

\section{Economic and Human Impact of Infestations}

Although not quantified, direct damage to the germ of rice (87) by L. bostrychophila, L. entomophila, and L. paeta and to wheat kernels by L. bostrychophila (54) has been recorded. Under laboratory conditions, McFarlane (50) estimated a weight loss of $5 \%$ and discernible deterioration in the quality of milled rice as a direct result of heavy infestations of L. bostrychophila over a six-month period. In a similar experiment, Kučerová (40) measured an average weight loss of $9.7 \%$ of broken wheat kernels due to infestations of $L$. bostrychophila for three months. This weight loss was correlated with progeny production.

Figures on actual economic damage are difficult to obtain, as in most cases this information is considered proprietary in commercial operations. In addition, it is often the presence of psocids in a commodity rather than any measurable damage that triggers control interventions and threatens market access, as is the case for beetle and moth pests (79). Major costs, therefore, are prevention of damage and action taken against infestations to ensure acceptance of the commodity by markets and quarantine authorities. Damage attributable to heavy psocid infestation has been estimated for commercial rice storage in India (40,000 tonnes) and Indonesia (150,000 tonnes) (38) where annual costs were calculated to be $£ 115,000$ (US\$180,000) and $£ 50,000$ (US\$75,000), respectively, in 1994. These costs included weight loss and cleaning costs involving both labor and materials. Weight loss was $0.17 \%$ during the four months of storage from a stable infestation of 
4,000 psocids $/ \mathrm{kg}$. In a recent study it was revealed that, although weight loss due to L. entomophila and $L$. paeta infestations was low in intact kernels $(0.2 \%$ and $0.4 \%$, respectively) compared with damaged wheat seeds ( $8.5 \%$ and $3.3 \%$, respectively), germination in intact kernels was reduced by $32 \%$ owing to L. paeta infestations (27).

Large psocid infestations have significant effects on health and safety. Psocids swarm over storage walkways and ladders, making them slippery and exposing workers to risk of injury (38, 44, 84). L. bostrychophila is commonly found in homes $(86,101)$, although L. brunnea and L. decolor have also been recorded (11). Psocids have been implicated in the development of allergies in workers, caused by transmission of microorganisms (104), and psocids may be responsible for transmitting bacterial diseases $(68,98)$, although there is no direct evidence for this. Instances of delusory parasitosis caused by psocids have also been reported $(34,100)$.

\section{BIOLOGY AND ECOLOGY}

\section{Laboratory Rearing}

The ability to culture insects in the laboratory is a prerequisite for obtaining detailed life-history data and greatly facilitates initial screening and optimization of management options. Fortunately, psocids are relatively easy to rear on stored products $(58,71)$ as long as $\mathrm{RH}$ is between $70 \%$ and $80 \%$. The key attributes of Liposcelis, including the ease with which they can be cultured, small size, short life cycle, high reproductive rates, worldwide distribution, and occurrence of multiple species, suggest that these insects will provide excellent model organisms for many aspects of biology.

\section{Immature Development}

Psocids are paurometabolous insects, with eggs developing into adults through simple, incomplete metamorphosis involving several nymphal stages that resemble small adults. Generally, psocids can develop from egg to adult at temperatures ranging from $20^{\circ} \mathrm{C}$ to $40^{\circ} \mathrm{C}$, depending on the species (Supplemental Table 1), although development from egg to adult at temperatures lower than $20^{\circ} \mathrm{C}$ has not been tested. Duration of egg development varies from $15-24$ days at $20^{\circ} \mathrm{C}$ to 4-8 days at $32.5-35^{\circ} \mathrm{C}$, which is generally longer than that for most other stored-product insect pests. Nymphal development varies with species but ranges from $22-53$ days at $20^{\circ} \mathrm{C}$ to $8-24$ days at $32.5-35^{\circ} \mathrm{C}$ (Supplemental Tables $\mathbf{1}$ and 2). Four nymphal instars is typical, with most mortality occurring in the first instar $(71,72)$ (Supplemental Table 3). For bisexual species, females always have more instars than males and take longer to develop. Time taken to develop from egg to adult varies from $42-72$ days at $20^{\circ} \mathrm{C}$ to $14-30$ days at $32.5-35^{\circ} \mathrm{C}$ (Supplemental Table 1). L. paeta (106) and $L$. decolor (95) have the shortest egg to adult development times at $32.5-35^{\circ} \mathrm{C}$, which may help explain why they are two of the most economically important psocid pest species worldwide. However, L. entomophila, another worldwide pest species, tends to have longer egg to adult development times than other species (108). The percentage of the immature life (egg and nymphal stages) spent in the egg stage varies between $19.7 \%$ and $52.3 \%$ and is not correlated with temperature.

The preoviposition period can be as short as 1 day at $37.5^{\circ} \mathrm{C}$ for L. paeta (106) and as long as 18 days at $20^{\circ} \mathrm{C}$ for L. bostrychophila (107) (Supplemental Table 4). The oviposition period ranges from 18 days at $37.5^{\circ} \mathrm{C}$ for $L$. decolor (95) and as long as 145 days at $22.5^{\circ} \mathrm{C}$ for $L$. rufa (26) (Supplemental Table 5). Adult longevity varies from 21 days at $35^{\circ} \mathrm{C}$ for L. badia (37) to as long as 229 days at $22.5^{\circ} \mathrm{C}$ for $L$. rufa (26) (Supplemental Table 6). Lifetime fecundity can vary greatly
Delusory parasitosis: a disorder in which patients have a strong but erroneous belief that they are infested with parasites 
among psocid species. For example, L. yunnanensis Li \& Li laid only 10 to 33 eggs at $20-37.5^{\circ} \mathrm{C}$ (31), whereas L. decolor and L. paeta laid over 100 eggs $(95,106)$ (Supplemental Table 7).

Parthenogenesis: the development of an unfertilized gamete (usually an egg) into a new individual

Symbiosis: a close and often long-term interaction between two or more individuals of different species

\section{Population Growth}

Understanding the factors that influence population growth is important when making pest management decisions and predicting the potential geographical distribution of psocids. Environmental temperature and $\mathrm{RH}$ are major determinants of the rate of psocid population growth. Experimental evidence shows that psocid populations increase at temperatures ranging from $22.5^{\circ} \mathrm{C}$ to $42^{\circ} \mathrm{C}$ (Supplemental Table 8). Population levels did not increase, however, in the few tests conducted below $22.5^{\circ} \mathrm{C}$, which included temperatures as low as $15^{\circ} \mathrm{C}(87)$, but five $L$. paeta females produced over 250 progeny in 56 days at $42^{\circ} \mathrm{C}(87)$. L. paeta is the only species known to increase in population level at temperatures above $37.5^{\circ} \mathrm{C}$. In general, greatest population growth occurs at temperatures of $30-32.5^{\circ} \mathrm{C}$ and $\geq 70 \% \mathrm{RH}$, except for $\mathrm{L}$. paeta, for which population growth is greatest at $35^{\circ} \mathrm{C}$ at $80 \% \mathrm{RH}(87)$. At $\mathrm{RH}$ below $70 \%$, greatest population growth occurs at cooler temperatures, presumably because the combination of high temperature and low humidity results in reduced survival. In laboratory studies, no live psocids have been found when reared at $\leq 50 \% \mathrm{RH}$; however, L. brunnea, L. pearmani Lienhard, and L. rufa populations all increased when reared at $55 \% \mathrm{RH}(2,25,72)$. L. brunnea is the only species studied so far that had a greater increase in population at $\leq 70 \%(63 \% \mathrm{RH})$ than at $\geq 70 \%(75 \% \mathrm{RH})(72)$, although L. entomophila and $L$. paeta have greater increase in population at $70 \% \mathrm{RH}$ than at $80 \% \mathrm{RH}$ (87). Generally, 70-80\% RH appears optimal for growth for most psocid species (Supplemental Table 8).

Both grain type and quality can affect psocid population growth. Experiments using L. bostrychophila, L. decolor, L. entomophila, and L. paeta showed that more psocids were produced on sorghum, wheat, and rice than on maize or oats (9). In contrast, maize was optimal for population growth of L. yunnanensis (32). Population growth was greater on durum wheat than on seven other classes of wheat (9). Adding cracked wheat to whole kernels generally did not change population growth of L. bostrychophila or L. paeta, but there was an increase in the rate of L. decolor population growth when the proportion of cracked wheat was $20 \%$ or greater (9).

\section{Endosymbiotic Bacteria, Parthenogenesis, and Genetic Diversity}

Endosymbiotic intracellular bacteria are common in invertebrates $(20,113)$ and can influence reproduction and other fitness-related traits of their hosts (77). They have been detected in the usually parthenogenic species $L$. bostrychophila [the only known sexually reproducing population of this species occurs on a remote Hawaiian island (56)] but are absent from sexually reproducing species, including L. corrodens, L. entomophila, L. brunnea, and L. paeta $(78,118)$. An exception is the discovery of Wolbachia infection in L. tricolor (24).

Wolbacbia-like strains of bacteria have been detected in the ovaries and developing oocytes of L. bostrychophila from the United Kingdom and Australia $(51,117)$. These endosymbionts were subsequently identified as Rickettsia (78), and removal of this infestation resulted in complete cessation of egg-laying but no other effect was apparent. The endosymbiont in L. bostrychophila has been identified as Rickettsia felis, a human pathogen transmitted by fleas that causes serious morbidity and occasional mortality $(13,96)$. Whether $R$. felis in psocids causes disease in vertebrates is not known. A population of L. bostrychophila infected with "Candidatus Cardinium" was detected in China (105). Removal of these bacteria resulted in a reduced reproductive rate and a longer generation time (36). Removal of Wolbachia infection from L. tricolor resulted in a $\sim 20 \%$ reduction in egg-laying, shorter adult female longevity, longer development times, and lower rates of survival (24). 
These bacteria are symbiotic and mutualistic, conferring significant fitness advantages to infected individuals. Parthenogenic reproduction appears key to the worldwide success of L. bostrychophila. Without the need to mate to reproduce, this species can potentially double its reproductive rate. L. bostrychophila has the highest population growth rate of any psocid species tested (87). Furthermore, despite an expectation that asexual reproduction reduces genetic variation, surveys indicate that populations of $L$. bostrychophila are highly diverse. For example, 47 distinct allozyme morphs were found in 116 British populations of L. bostrychophila. This high level of interpopulation variation appeared to be randomly distributed and showed no apparent trends (1). High overall genetic variability was also observed in L. bostrychophila populations from Australia, China, Mexico, Spain, United Kingdom, and United States analyzed using RAPD (randomly amplified polymorphic DNA) markers $(45,52)$. In contrast, sequences from both mitochondrial and nuclear DNA from L. entomophila, a sexually reproducing species, had lower levels of genetic diversity than L. bostrychophila (111). Microsatellite markers providing evidence for relatively low levels of genetic variation and only moderate levels of gene flow were also found in L. decolor (53), although this finding may have been influenced by the presence of null alleles.

\section{Spatial Distribution}

Grain, along with associated insects, has been transported around the world for millennia. Thus, the major pest species of grain, including psocids, are broadly distributed worldwide. For example, molecular methods have shown that L. bostrychopbila was probably first introduced into eastern Australia and then spread to other regions of the country; however, there have also been multiple introductions from a range of sources (52). In Australia, L. decolor was most common in cooler regions, whereas L. entomophila had a warm temperate to tropical distribution (86). L. decolor was found only in central and on-farm grain storage structures. L. entomophila was found most frequently in central storage structures and in mills, infrequently in farm storage structures, and not at all in homes. L. bostrychophila was found across Australia, and it was the only species found in homes. It was also common in on-farm storage structures and mills but was found less frequently in bulk storage structures (86).

Like stored-product beetles, psocids are found throughout the year in grain stored in temperate regions, although numbers trapped are reduced in winter (75). Infestation by only one psocid species can occur. For example, L. entomophila was the only species found to infest stored oats in the United States (3) and in tobacco-processing houses in Zimbabwe (48), and Sinha (93) rarely found two psocid species in the same bin in a number of multiyear studies conducted over a 20 -year period in Canada. In a study of two farm bins in the United States, only L. entomophila was present but this species was replaced by $L$. decolor following fumigation with phosphine (75). In Australia, however, infestation of grain by multiple psocid species is more common (66). When there were differences in the spatial distribution of psocids in the bins, more psocids were located at the center of the bin, where there is usually more dockage, higher moisture, and higher temperatures in the autumn (75). In addition, a higher number of psocids were found at a depth of 0.85-1.96 $\mathrm{m}$ than at $0-0.84 \mathrm{~m}$, and this may have been a result of higher temperatures at lower depths in the grain mass in the autumn as surface temperatures decreased (75).

\section{Sampling and Trapping}

Cost-effective sampling methods that can be used to accurately estimate psocid populations are fundamental to the development and implementation of any psocid pest management plan. Because of the difficulty and cost of manually sampling grain bulks, a number of traps, some of which use
Mutualism: a symbiotic association of usually two individuals of different species in which each individual benefits

Microsatellite markers: nucleotide repeats in DNA sequences used to identify genetically distinct groups of organisms

Dockage: impurities in harvested wheat including weed seeds, stems, chaff, straw, grain other than wheat, and below standard kernels 
lures or baits, have been developed as detection and sampling tools. Devices developed for sampling beetle populations range from simple baited refuges made from corrugated cardboard (22) to traps that automatically count insect catch (79). Some of these devices have been evaluated and adopted for monitoring psocids in grain storage structures.

In silos where access is limited, corrugated cardboard refuges have been shown to be highly cost-effective. Packing whole wheat flour within the corrugations caught more L. entomophila than other baits, including whole wheat grain, whole wheat flour/carob powder, or wheat germ oil, in a trial undertaken in a disused grain terminal in Australia (114). The refuges needed to be left on the grain for at least 3 days. Other devices including probe traps $(27 \times 370 \mathrm{~mm})$, cone-shaped pitfall traps $(125 \times 95 \mathrm{~mm})$, and grain-baited bags were compared in trials in seven silos at three feed milling companies in northeastern Australia (90).

Probe traps caught just as many psocids (L. bostrychophila, L. entomophila, and L. paeta) as manual (spear) sampling, but pitfall traps were more reliable as they could detect low density and thus gave early warning of infestations. However, all trapping methods correlated with manual sampling and more than one trap per silo did not improve correlation. Reasonable correlation between manual sampling and several trapping devices was found in trials conducted over two years in two steel farm bins (32.6 ton capacity) in Kansas (73). Although probe traps caught the greatest number of psocids (L. entomophila), it was concluded that corrugated cardboard refuges, placed either on the surface of the grain or on the underside of bin hatches, were the most cost-effective method as they were inexpensive and quick to inspect. The data from these trials were used to evaluate the utility of binomial (presence-absence) and numerical sampling using cardboard refuges for monitoring populations of L. decolor and L. entomophila (74). Statistical analysis revealed that at densities of 25 psocids or fewer per refuge, numerical sampling was the most efficient method as only 10 refuges per bin are required, whereas at densities of 25-100 psocids, binomial sampling using 20 refuges per bin was the most efficient sampling strategy.

\section{Behavior}

Psocids are active insects, and L. bostrychophila and L. entomophila have been recorded to move at velocities of 3.6 and $4.9 \mathrm{~mm} / \mathrm{s}$, respectively (28). Large numbers of $L$. decolor have been observed leaving grain bins when the RH in the bin drops over the course of the day. Rees (86) suggested that female psocids, in particular, tended to leave the bin to obtain moisture needed for egg production and returned to the bin when the RH increased. Similar diurnal fluctuations have been reported for L. entomophila on stored rice stacks in Indonesia (38). Interaction between psocids and other pests in the commodity, apart from a report on predation of Indianmeal moth [Plodia interpunctella (Hübner)] eggs by L. bostrychophila (47) and an observation of the predation of psocids by predatory mites (82), is poorly understood.

\section{MANAGEMENT TACTICS: CHEMICAL}

\section{Contact Insecticides}

An apparent tolerance to insecticides was observed in a number of early control failures with psocids. Admixing permethrin, fenitrothion, and malathion with paddy rice and spraying surfaces of bag stacks failed to suppress populations of L. bostrychophila and L. entomophila in Indonesia and India $(35,82,84,92)$. Whether these failures were due to resistance or other factors was not established. Similarly, initial laboratory evaluations of the efficacy of contact insecticides against psocids showed variable degrees of tolerance of $L$. bostrychophila to pyrethroids, including 
permethrin, cypermethrin, and deltamethrin (103); L. entomophila and L. bostrychophila to the organophosphates fenitrothion, malathion, and pirimiphos-methyl (42); and L. bostrychophila to the insect growth regulators methoprene and fenoxycarb $(16,41)$.

The complex response of psocids to insecticides was confirmed by a series of comprehensive studies using field-collected populations. Treatments registered to control beetle and moth grain pests were tested against several Liposcelis species at registered rates. These experiments showed that L. bostrychophila and L. decolor could be effectively controlled by fenitrothion, chlorpyrifosmethyl, and pirimiphos-methyl and by bioresmethrin and bifenthrin synergized with piperonyl butoxide, but that both species were tolerant to deltamethrin, carbaryl, and methoprene $(21,57,62$, 64). In contrast, L. entomophila and L. paeta were tolerant to all these treatments $(21,64)$. Variable degrees of tolerance of these Liposcelis species were also recorded against the bacterium-derived spinosad $(7,8,67)$, imidacloprid (65), and diatomaceous earth (5). Together these experiments demonstrate that certain psocid species possess a naturally higher tolerance to contact insecticides compared with other insect pests of stored products.

Interspecific differences in response to chemical treatments have serious implications for control in the field, as psocid infestations often involve more than one species, particularly if either L. entomophila or L. paeta is involved $(18,64,67,85)$. Efforts to combine treatments to overcome this problem have yielded variable results. Mixtures of chlorpyrifos-methyl and bifenthrin + piperonyl butoxide applied to sorghum in a silo-scale trial in Australia (21) provided up to 7 months of protection against $L$. bostrychophila and $L$. decolor, but only 3 months of protection against $L$. paeta, and failed to achieve complete mortality against L. entomophila. Moreover, in laboratory experiments, a mixture of chlorpyrifos-methyl + deltamethrin and pirimiphos-methyl were superior to either spinosad or pyrethrum alone at protecting wheat, rice, and maize against L. paeta, L. entomophila, and L. bostrychophila (6). However, spinosad + chlorpyrifos-methyl mixtures successfully protected wheat against $L$. bostrychophila, L. entomophila, L. paeta, and L. decolor for up to 3 months (66), but fell short of the required 9 months protection expected from a registered grain protectant in Australia.

\section{Storage Structure Treatments}

Stored-product psocids are wingless and move actively over the commodity and the walls and other parts of the storage structure. This behavior provides storage managers an opportunity to control infestations by applying contact insecticides to the structure of the storage. Most storage structures, grain-processing facilities, and food storage warehouses worldwide are composed of either galvanized steel, concrete, or both. Extensive laboratory evaluations of several registered surface treatments in Australia exposed the difficulties in achieving long-term control (6-9 months) of L. bostrychophila, L. decolor, L. entomophila, and L. paeta on concrete surfaces (19, 60-62). In contrast, carbaryl combined with an organophosphate such as chlorpyrifos-methyl, pirimiphosmethyl, or azamethiphos applied to galvanized steel controlled these four species for 9 months. In addition, $\beta$-cyfluthrin and chlorfenapyr are effective against L. bostrychophila and L. entomophila at their current US registration rates for relatively short periods on concrete surfaces (28), whereas the insect growth regulator pyriproxyfen is unable to provide complete control even for only 35 days after application of L. bostrychophila, L. decolor, or L. paeta (4). In the only study of the potential use of insecticidal aerosols against psocids, esfenvalerate, methoprene, and a combination of these two insecticides were ineffective against all major species (70).

\section{Fumigants}

Investigations into why L. entomophila survive fumigations with phosphine established that the egg stage was the most tolerant (80). The relatively long egg stage of psocids can pose a real challenge to
Diatomaceous earth: soft, siliceous sedimentary rock consisting of fossilized remains of diatoms, a type of hard-shelled, mostly unicellular algae 


\section{RESISTANCE TO PHOSPHINE: A WORLDWIDE CHALLENGE}

Phosphine's formulation, application, and mode of action are unique. Its low cost and acceptance by markets and environmental authorities, coupled with a lack of viable alternatives, make it the key treatment for biosecurity, food security, and market access of dry food commodities worldwide.

Key pests, however, are evolving resistance to phosphine. The challenge is to develop strategies that allow its continued use despite resistance.

Unlike resistance to conventional insecticides, phosphine resistance is mediated by two major genes that separately show only weak levels of resistance but together synergize to produce a high level of resistance. The need for insects to be homozygous for both genes for full expression of resistance delays spread of resistance and provides time to develop and implement management strategies.

Successful management is based on tactics and responses informed by a monitoring program and grounded on research. Manipulating the variables that affect phosphine toxicity has greatly improved control, even of resistant insects. New molecular methods are unraveling the genetics and mechanisms of resistance, as well as its mode of action, and providing rapid and accurate diagnostic tools. However, although we have some understanding of how phosphine is selected, we are only beginning to comprehend how insect ecology influences resistance frequencies and gene flow.

control efforts. It was not determined whether these insects were resistant to phosphine. However, widespread resistance was later confirmed for this species in China (17) (see sidebar, Resistance to Phosphine: A Worldwide Challenge). Very high levels of resistance to phosphine have been detected in L. bostrychophila populations from India (84) and Australia (59, 63). Not only is the egg stage the most tolerant stage in this species, exposure to phosphine significantly delays egg hatch. The delay occurs to a limited extent in susceptible insects but is much stronger in resistant individuals (63). In addition, the length of the delay correlates with phosphine concentrationhigher concentrations result in longer times to hatch. This phenomenon was not observed in L. entomophila (80).

The nature of phosphine is such that despite resistance, concentration and exposure period protocols that will control resistant insects can be found. Higher concentrations and longer fumigation periods were developed for resistant L. bostrychophila (59) over a temperature range of $20-35^{\circ} \mathrm{C}$ under humidity regimes of $55 \%$ and $70 \% \mathrm{RH}$. It was found that at any concentration of phosphine, a combination of higher temperature and lower humidity provides the shortest fumigation period to control this resistant psocid.

There has been some limited evaluation of other fumigants for efficacy against psocids, which reinforced the robustness of the egg stage and the variability of species' responses to chemicals. Experiments using ozone $\left(\mathrm{O}_{3}\right)(15)$ showed that eggs of L. bostrychophila and L. paeta survived $70 \mathrm{ppm}$ for 4 days (highest rate tested), although adults were controlled after one day. Sulfuryl fluoride is a potential replacement for methyl bromide or phosphine. Experiments on the activity of this fumigant against several psocid species (10) showed that dosages well below the maximum recommended dose of $1,500 \mathrm{~g}-\mathrm{h} / \mathrm{m}^{3}$ (or $31.25 \mathrm{~g} / \mathrm{m}^{3}$ for $48 \mathrm{~h}$ ) controlled adults and nymphs of all major pest species except for $L$. decolor. In contrast, eggs of $L$. decolor were completely controlled at $72 \mathrm{~g} / \mathrm{m}^{3}$, whereas complete mortality of L. paeta was not achieved at $96 \mathrm{~g} / \mathrm{m}^{3}$ in $48 \mathrm{~h}$, dosages that are two and three times the label rate, respectively. 


\section{MANAGEMENT TACTICS: NONCHEMICAL}

The difficulties encountered controlling psocids with fumigants and contact insecticides have stimulated research into other tactics that could be used as alternatives or used to support chemical application.

\section{Drying and Cooling}

As discussed above, psocids thrive within the RH range of 70-85\% (39) but their populations suffer rapid decline at RH less than $\sim 60 \%$ (23). For example, L. knullei, L. rufus, and L. bostrychophila cannot survive more than 10 days if they are kept below 58\% RH (39). Reducing commodity moisture content and hence the equilibrium RH is crucial for controlling these insects, although this is not practical in many cases. However, because psocids have the ability to obtain moisture from the atmosphere, reducing the temperature of the commodity to limit population growth is also crucial. For example, observation of L. entomophila in tobacco-processing buildings on farms in Zimbabwe (49) showed a significant drop in psocid numbers once the humidity and temperature levels in the storage structure were kept below $70 \% \mathrm{RH}$ and $18^{\circ} \mathrm{C}$, respectively.

\section{Heat Disinfestation}

Evidence from life table experiments suggests that psocid infestations could be controlled by moderately elevating temperatures of the commodity $(87,107)$. The egg stage is the most tolerant (12) and extensive experiments conducted at $43-51^{\circ} \mathrm{C}$ for $1-150$ h showed that heating to $46^{\circ} \mathrm{C}$ over a period of $35 \mathrm{~h}$ controls eggs of L. bostrychophila, L. decolor, and L. paeta. L. decolor was the most tolerant species at $46-51^{\circ} \mathrm{C}$ and L. paeta was most tolerant below $46^{\circ} \mathrm{C}$ but most susceptible at $47-51^{\circ} \mathrm{C}$. L. bostrychophila was generally less tolerant than $L$. decolor (12). The potential of heat treatment was demonstrated in a full-scale trial in empty concrete silos in Oklahoma (69). Heat was applied to the silos with the aim of achieving $49^{\circ} \mathrm{C}$ for $6 \mathrm{~h}$ in all parts of the structure. Complete control of L. corrodens in cages was achieved, but $L$. decolor survived in areas where temperatures reached only $40.6-46.9^{\circ} \mathrm{C}$. The trial made it clear that this technology would need to be used in conjunction with thorough storage cleanup as the presence of grain residues compromised the efficacy of the treatment. Psocid species vary in their tolerance to heat treatment $(12,29)$, and these differences may be due partly to the physiological protection afforded by the generation of heat shock proteins in some species. L. entomophila exposed to temperatures of $37.5-47.5^{\circ} \mathrm{C}$ produced small heat-inducible proteins, HIP23 and HIP27, which was correlated with lethal time estimates (29). This species is most common in warm temperate to tropical regions (86) and warmer parts of grain storage structures (69), and the ability to generate protective heat shock proteins in response to high temperatures may help explain its predominance in those areas.

\section{Diatomaceous Earths}

The efficacy of three commercial formulations of diatomaceous earth against $L$. decolor and L. entomophila at recommended application rates on three grain types was tested in the laboratory (5). Efficacy was influenced little by grain type, and formulations were nearly as effective. However, after 7 days exposure to treated grain at $30^{\circ} \mathrm{C}$ and $75 \% \mathrm{RH}$, the mortality of adults was only $\sim 50 \%$ and reproduction was suppressed but not to a satisfactory level. In general, L. decolor was more tolerant than L. entomophila. These experiments were undertaken at relatively high 
humidity, and it is possible that diatomaceous earth would be much more effective in systems with lower atmospheric humidity. Indeed, field trials undertaken in large, disused grain silos at a maritime terminal in warm temperate Australia demonstrated that diatomaceous earth can dramatically reduce L. entomophila populations (114).

\section{Controlled and Modified Atmosphere}

Air with concentrations of carbon dioxide $\left(\mathrm{CO}_{2}\right)$ at 40-50\% will control L. entomophila (43) and L. bostrychophila $(14,88)$ populations; a combination of $35 \% \mathrm{CO}_{2}$ and $64 \%$ nitrogen $\left(\mathrm{N}_{2}\right)$ is effective against $L$. bostrychophila $(109,110)$. However, these methods require an exposure period of at least 3 weeks to achieve complete control.

\section{Natural Enemies}

There is anecdotal evidence of mites [Blattisocius tarsalis (Berlese) (89), Cheyletus malaccensis Oudemans, and Cheletomorpha lepidopterorum (Shaw) (76)] and pseudoscorpions [Withius piger (Simon) (76)] preying on psocids. However, owing to possible allergic sensitivities of humans, the practical application of these organisms in psocid management has never been evaluated.

\section{CONCLUSIONS}

This review synthesizes the significant experimental data available on psocid biology, ecology, and control tactics, and explains how this understanding might support effective management of these pests. Life-history analyses of the major pest species have indeed delineated their strengths and exposed some weaknesses. There is little or no increase in population for major species at temperatures lower than $22^{\circ} \mathrm{C}$. However, we have only a preliminary understanding of psocid field ecology and the factors that trigger their characteristic massive infestations. In addition, the literature demonstrates that our traditional pest management tools are inadequate to effectively manage psocid outbreaks. Their tolerance to grain-protecting chemicals and the development of resistance to phosphine coupled with their unique behavior and capability for rapid population growth present serious challenges to the development of effective pest management programs. That there are multiple pest species and that infestations can comprise more than one species add significantly to the challenge. This review has revealed that we are still relying on reactive chemical treatments and that alternatives to chemicals are poorly developed, with data limited mostly to a few laboratory-scale experiments. Although relatively simple population-monitoring tools are available, we do not have a clear understanding of the key factors needed for an effective pest management strategy. Finally, we hope that our presentation of this fascinating genus of insects consisting of about 100 species and with many attributes, including rapid population growth, short generation time, presence of endosymbiotic bacteria, and ease of culturing, recommends them as ideal models systems for biology, ecology, and evolution.

\section{SUMMARY POINTS}

1. Previously regarded as a nuisance and incidental invader, psocids of the genus Liposcelis have become major pests of stored products worldwide, particularly in tropical and warm temperate regions. The four major cosmopolitan pest species are L. bostrychophila, L. decolor, L. entomophila, and L. paeta. 
2. Psocids are small, active, omnivorous insects with short life cycles, high reproductive rates, and long adult lives. They thrive in warm temperatures at an $\mathrm{RH}$ of $70-80 \%$. In addition, they have the ability to absorb water from the atmosphere.

3. Chemical treatments designed to control beetle and moth pests are failing against psocids. It appears that psocids are tolerant to most treatments and their populations recover faster from poorly applied treatments compared with the beetle species that normally would prey on them. A significant challenge is that infestations can comprise more than one species, each of which has different responses to treatments.

4. A number of sampling devices, normally used for beetle pests, have been tested for monitoring psocid infestations. Catch number correlated with manual sampling in all devices. The corrugated cardboard trap was found to be the most cost-effective, but pitfall traps could detect lower densities of psocids.

5. Tolerance to contact insecticides varies among species but organophosphorus materials are most effective in general. The egg stage is quite tolerant to the fumigants phosphine and sulfuryl fluoride, and strong resistance to phosphine has been detected in L. bostrychophila.

6. Nonchemical alternatives are poorly developed and are desperately needed as a basis for integrated pest management strategies.

\section{FUTURE ISSUES}

1. Research is required to comprehend movement of psocids in the landscape and initiation of colonization of stored products; an understanding of adaptations to the storage environment and population growth rates in relation to storage type, climate, and stored product is also needed.

2. A better understanding of genetic basis for adaptations such as heat stress, growth and development, and development of resistance to chemical treatments is required.

3. Development of effective pest management tactics, including new chemical options and applications and nonchemical, biorational alternatives, and integration of these into pest management strategies incorporating all major pest species and major commodities are essential.

4. Effective application and timing of pest management actions require development of decision aids and systems.

5. Rapid, accurate molecular methods for species identification are required.

\section{DISCLOSURE STATEMENT}

The authors are not aware of any affiliations, memberships, funding, or financial holdings that might be perceived as affecting the objectivity of this review. 


\section{ACKNOWLEDGMENTS}

The authors extend sincere thanks to their colleagues Paul Fields, Greg Daglish, and Christos Athanassiou for their constructive criticism of an earlier draft of the review. Manoj Nayak and Patrick Collins would like to acknowledge the support of the Australian Government's Cooperative Research Centres Program. Mention of trade names or commercial products in this publication is solely for the purpose of providing specific information and does not imply recommendation or endorsement by the US Department of Agriculture.

\section{LITERATURE CITED}

1. Ali N, Turner B. 2001. Allozyme polymorphism and variability in permethrin tolerance in British populations of the parthenogenetic stored product pest Liposcelis bostrychophila (Liposcelididae, Psocoptera). 7. Stored Prod. Res. 37:111-25

2. Aminatou BA, Gautam SG, Opit GP, Talley J, Shakya K. 2011. Population growth and development of Liposcelis pearmani (Psocoptera: Liposcelididae) at constant temperatures and relative humidities. Environ. Entomol. 40:788-96

3. Arbogast RT, Kendra PE, Weaver DK, Shuman D. 2000. Insect infestation of stored oats in Florida and field evaluation of a device for counting insects electronically. 7. Econ. Entomol. 93:1035-44

4. Athanassiou CG, Arthur FH, Kavallieratos NG, Throne JE. 2011. Efficacy of pyriproxyfen for control of stored-product psocids (Psocoptera) on concrete surfaces. F. Econ. Entomol. 104:1765-69

5. Athanassiou CG, Arthur FH, Opit GP, Throne JE. 2009. Insecticidal effect of diatomaceous earth against three species of stored-product psocids on maize, rice, and wheat. F. Econ. Entomol. 102:1673-80

6. Athanassiou CG, Arthur FH, Throne JE. 2009. Efficacy of grain protectants against four psocid species on maize, rice and wheat. Pest Manage. Sci. 65:1140-46

7. Athanassiou CG, Arthur FH, Throne JE. 2009. Efficacy of spinosad in layer-treated wheat against five stored-product insect species. 7. Stored Prod. Res. 45:236-40

8. Athanassiou CG, Arthur FH, Throne JE. 2010. Effects of short exposures to spinosad-treated wheat or maize on four stored-grain insects. F. Econ. Entomol. 103:197-202

9. Athanassiou CG, Opit GP, Throne JE. 2010. Influence of commodity type, percentage of cracked kernels, and wheat class on population growth of stored-product psocids (Psocoptera: Liposcelidae). 7. Econ. Entomol. 103:985-90

10. Athanassiou CG, Phillips TW, Aikins MJ, Hasan MM, Throne JE. 2012. Effectiveness of sulfuryl fluoride for control of different life stages of stored-product psocids (Psocoptera). F. Econ. Entomol. 105:282-87

11. Baz A, Monserrat VJ. 1999. Distribution of domestic Psocoptera in Madrid apartments. Med. Vet. Entomol. 13:259-64

12. Examines the tolerance of major species to heat, indicating the potential of this control method.
12. Beckett SJ, Morton R. 2003. The mortality of three species of Psocoptera, Liposcelis bostrychophila (Badonnel), Liposcelis decolor (Pearman) and Liposcelis paeta (Pearman), at moderately elevated temperatures. F. Stored Prod. Res. 39:103-15

13. Behar A, McCormick LJ, Perlman SJ. 2010. Rickettsia felis infection in a common household insect pest, Liposcelis bostrychophila (Psocoptera: Liposcelidae). Appl. Environ. Microbiol. 76:2280-85

14. Bell CH, Spratt EC, Llewellin BE. 1990. Current strategies for the use of controlled atmospheres for the disinfestation of grain under UK conditions. In Fumigation and Controlled Atmosphere Storage of Grain, ed. BR Champ, HJ Banks, E Highley, pp. 251-53. ACIAR Proc. No. 25. Canberra, Aust.: ACIAR

15. Bonjour EL, Opit GP, Hardin J, Jones CL, Payton ME, Beeby RL. 2011. Efficacy of ozone fumigation against the major grain pests in stored wheat. F. Econ. Entomol. 104:308-16

16. Büchi R. 1994. Effects of two insect growth regulators on the booklouse, Liposcelis bostrychophila. F. Stored Prod. Res. 30:157-61

17. Cao Y, Son Y, Sun GY. 2003. A survey of psocid species infesting stored grain in China and resistance to phosphine in field populations of Liposcelis entomophila (Enderlein) (Psocoptera: Liposcelididae). In Advances in Stored Product Protection, Proc. 8th Int. Working Conf. Stored Prod. Prot., ed. PF Credland, DM Armitage, CH Bell, PM Cogan, E Highley, pp. 662-67. Wallingford, UK: CAB Int. 
18. Champ BR, Smithers CN. 1965. Insects and mites associated with stored products in Queensland. 1. Psocoptera. Qld. 7. Agric. Anim. Sci. 22:259-62

19. Collins PJ, Nayak MK, Kopittke R. 2000. Residual efficacy of four organophosphate insecticides on concrete and galvanized steel surfaces against three liposcelid psocid species (Psocoptera: Liposcelidae) infesting stored products. 7. Econ. Entomol. 93:1357-63

20. Corsaro D, Venditti D, Padula M, Valassina M. 1999. Intracellular life. Crit. Rev. Microbiol. 25:39-79

21. Daglish GJ, Wallbank BE, Nayak MK. 2003. Synergized bifenthrin plus chlorpyrifos-methyl for control of beetles and psocids in sorghum in Australia. 7. Econ. Entomol. 96:525-32

22. De Coursey JD. 1931. Trapping confused flour beetles. F. Econ. Entomol. 24:1079-81

23. Devine TL. 1978. The turnover of the gut contents (traced with inulin-carboxyl- ${ }^{14} \mathrm{C}$ ), tritiated water and ${ }^{22} \mathrm{Na}$ in three stored product insects. 7. Stored Prod. Res. 14:189-211

24. Dong P, Wang JJ, Hu F, Jia FX. 2007. Influence of Wolbachia infection on the fitness of the storedproduct pest Liposcelis tricolor (Psocoptera: Liposcelididae). 7. Econ. Entomol. 100:1476-81

25. Gautam SG, Opit GP, Giles KL. 2010. Population growth and development of the psocid Liposcelis rufa (Psocoptera: Liposcelididae) at constant temperatures and relative humidities. 7. Econ. Entomol. 103:1920-28

26. Gautam SG, Opit GP, Giles KL. 2012. Effects of constant temperatures on reproductive parameters of the psocid Liposcelis rufa (Psocoptera: Liposcelididae). Entomol. Ornithol. Herpetol. S1:002

27. Gautam SG, Opit GP, Giles KL, Adam B. 2013. Weight loss and germination failure caused by psocids in different wheat varieties. F. Econ. Entomol. 106:491-98

28. Guedes RNC, Campbell JF, Arthur FH, Opit GP, Zhu KY, Throne JE. 2008. Acute lethal and behavioral sublethal responses of two stored-product psocids to surface insecticides. Pest Manage. Sci. 64:1314-22

29. Guedes RNC, Zhu KY, Opit GP, Throne JE. 2008. Differential heat shock tolerance and expression of heat-inducible proteins in two stored-product psocids. F. Econ. Entomol. 101:1974-82

30. Hagstrum DW, Subramanyam B. 2006. Fundamentals of Stored-Product Entomology. St. Paul, MN: AACC International

31. Hassan MW, Dou W, Chen L, Jiang HB, Wang JJ. 2011. Development, survival, and reproduction of the psocid Liposcelis yunnaniensis (Psocoptera: Liposcelididae) at constant temperatures. F. Econ. Entomol. 104:1436-44

32. Hassan MW, Dou W, Jiang HB, Wang JJ. 2010. Comparative population growth of the psocid Liposcelis yunnaniensis (Psocoptera: Liposcelididae) on different diets. Int. F. Insect Sci. 2:21-27

33. Hebert PDN, Ratnasingham S, de Waard JR. 2003. Barcoding animal life: cytochrome $c$ oxidase subunit 1 divergences among closely related species. Proc. R. Soc. B. 270:S96-99

34. Hickin N. 1985. Pest Animals in Buildings: A World Review. London: George Godwin. 385 pp.

35. Hodges RJ, Halid H, Sidik M, Conway JA. 1992. Cost efficiency of respraying store surfaces with insecticide to protect bagged milled rice from insect attack. Trop. Pest Manage. 38:391-97

36. Jia FX, Yang MS, Yang WJ, Wang JJ. 2009. Influence of continuous high temperature conditions on Wolbachia infection frequency and the fitness of Liposcelis tricolor (Psocoptera: Liposcelididae). Environ. Entomol. 38:1365-72

37. Jiang HB, Liu JC, Wang ZY, Wang JJ. 2008. Temperature-dependent development and reproduction of a novel stored product psocid, Liposcelis badia (Psocoptera: Liposcelididae). Environ. Entomol. 37:110512

38. Kleih U, Pike V. 1995. Economic assessment of psocid infestations in rice storage. Trop. Sci. 35:280-89

39. Knülle W, Spadafora RR. 1969. Water vapor sorption and humidity relationships in Liposcelis (Insecta: Psocoptera). 7. Stored Prod. Res. 5:49-55

40. Kučerová Z. 2002. Weight losses of wheat grains caused by psocid infestation (Liposcelis bostrychophila: Liposcelisdidae: Psocoptera). Plant Prot. Sci. 38:103-7

41. Kučerová Z, Zuska J. 1991. Susceptibility of the psocid pest Liposcelis bostrychophilus to methoprene and to a new juvenoid. In Proc. 5th Int. Work. Conf. Stored Prod. Prot., ed. F Fleurat-Lessard, P Ducom, pp. 565-70. Bordeaux: Impr. Médoc

42. Leong ECW, Ho SH. 1994. Relative tolerance of Liposcelis bostrychophila (Bad.) and L. entomophila (End.) to some organophosphorus and carbamate insecticides. Insect Sci. Appl. 15:343-49
19. First long-term (10 months) evaluation of limitations of insecticides applied to industrial surfaces.

38. Provides an economic assessment of impact and damage of infestation in large-scale storage structures.

39. Groundbreaking investigation of a key psocid survival adaptation to harsh environments. 
46. Encyclopedia of world Psocoptera species, including bibliography of all published literature on psocids.

63. Provides insight into reasons why psocids survive phosphine fumigation.
43. Leong ECW, Ho SH. 1990. Susceptibility of Liposcelis entomophilus (Enderlein) to carbon dioxide. In Fumigation and Controlled Atmosphere Storage of Grain, ed. BR Champ, HJ Banks, E Highley, pp. 268-69. ACIAR Proc. 25. Canberra, Aust.: ACIAR

44. Leong ECW, Ho SH. 1990. Techniques in the culturing and handling of Liposcelis entomophilus (Enderlein) (Psocoptera: Liposcelidae). 7. Stored Prod. Res. 26:67-70

45. LiZH, KučerováZ,Zhao S, Stejskal V, Opit G, Qin M. 2011. Morphological and molecular identification of three geographical populations of the storage pest Liposcelis bostrychophila (Psocoptera). F. Stored Prod. Res. 47:168-72

46. Lienhard C, Smithers CN. 2002. Pscoptera (Insecta) World Catalogue and Bibliography. Geneva: Instrumental Biodivers. V, Mus. Hist. Nat. 745 pp.

47. Lovitt AE, Soderstrom EL. 1968. Predation on Indian meal moth eggs by Liposcelis bostrychophilus. 7. Econ. Entomol. 61:1444-45

48. Mashaya N. 1999. Population dynamics of Liposcelis entomophila (Enderlein) (Psocoptera: Liposcelidae) in farm tobacco processing buildings. 7. Stored Prod. Res. 35:355-68

49. Mashaya N. 2001. Influence of ambient temperature and relative humidity on changes in numbers of a natural population of Liposcelis entomophila (Enderlein) (Psocoptera: Liposcelididae). F. Stored Prod. Res. 37:1-12

50. McFarlane JA. 1982. Damage to milled rice by psocids. Trop. Stored Prod. Inf. 44:3-10

51. Mikac KM. 2007. PCR confirms multiple Wolbachia strain infection in Australian and international populations of the invasive stored-product psocid Liposcelis bostrychophila (Badonnel). F. Stored Prod. Res. 43:594-97

52. Mikac KM, Clarke GM. 2006. Tracing the geographic origin of the cosmopolitan parthenogenetic insect pest Liposcelis bostrychophila (Psocoptera: Liposcelididae). Bull. Entomol. Res. 96:523-30

53. Mikac KM, FitzSimmons NN. 2010. Genetic structure and dispersal patterns of the invasive psocid Liposcelis decolor (Pearman) in Australian grain storage systems. Bull. Entomol. Res. 100:521-27

54. Mills JT, Sinha RN, Demianyk CJ. 1992. Feeding and multiplication of a psocid, Liposcelis bostrychophilus Badonnel (Psocoptera: Liposcelidae), on wheat, grain screenings, and fungi. F. Econ. Entomol. 85:1453-62

55. Mockford EL. 1993. North American Psocoptera. Gainesville, FL: Sandhill Crane Press. 455 pp.

56. Mockford EL, Krushelnycky PD. 2008. New species and records of Liposcelis Motschulsky (Psocoptera: Liposcelididae) from Hawaii with first description of the male of Liposcelis bostrychophila (Badonnel). Zootaxa 1766:53-68

57. Nayak MK. 2010. Potential of piperonyl butoxide-synergised pyrethrins against psocids (Psocoptera: Liposcelididae) for stored-grain protection. Pest Manage. Sci. 66:295-300

58. Nayak MK, Collins PJ. 2001. An improved method for mass rearing of three liposcelid psocids (Psocoptera: Liposcelidae) infesting stored commodities. 7. Stored Prod. Res. 37:323-28

59. Nayak MK, Collins PJ. 2008. Influence of concentration, temperature and humidity on the toxicity of phosphine to the strongly phosphine-resistant psocid Liposcelis bostrychophila (Badonnel) (Psocoptera: Liposcelididae). Pest Manage. Sci. 64:971-76

60. Nayak MK, Collins PJ, Kopittke RA. 2002. Comparative residual toxicities of carbaryl, deltamethrin and permethrin as structural treatments against three liposcelidid psocid species (Psocoptera: Liposcelididae) infesting stored commodities. 7. Stored Prod. Res. 38:247-58

61. Nayak MK, Collins PJ, Kopittke RA. 2003. Residual toxicities and persistence of organophosphorus insecticides mixed with carbaryl as structural treatments against three liposcelidid psocid species (Psocoptera: Liposcelididae) infesting stored grain. 7. Stored Prod. Res. 39:343-53

62. Nayak MK, Collins PJ, Pavic H. 2002. Long-term effectiveness of grain protectants and structural treatments against Liposcelis decolor (Pearman) (Psocoptera: Liposcelididae), a pest of stored products. Pest Manage. Sci. 58:1223-28

63. Nayak MK, Collins PJ, Pavic H, Kopittke RA. 2003. Inhibition of egg development by phosphine in the cosmopolitan pest of stored products Liposcelis bostrychophila (Psocoptera: Liposcelididae). Pest Manage. Sci. 59:1191-96

64. Nayak MK, Collins PJ, Reid SR. 1998. Efficacy of grain protectants and phosphine against Liposcelis bostrychophila, L. entomophila, and L. paeta (Psocoptera: Liposcelidae). 7. Econ. Entomol. 91:1208-12 
65. Nayak MK, Daglish GJ. 2006. Potential of imidacloprid to control four species of psocids (Psocoptera: Liposcelididae) infesting stored grain. Pest Manage. Sci. 62:646-50

66. Nayak MK, Daglish GJ. 2007. Combined treatments of spinosad and chlorpyrifos-methyl for management of resistant psocid pests (Psocoptera: Liposcelididae) of stored grain. Pest Manage. Sci. 63:104-9

67. Nayak MK, Daglish GJ, Byrne VS. 2005. Effectiveness of spinosad as a grain protectant against resistant beetle and psocid pests of stored grain in Australia. 7. Stored Prod. Res. 41:455-67

68. Obr S. 1978. Psocoptera of food-processing plants and storages, dwellings and collections of natural objects in Czechoslovakia. Acta Entomol. Bobemoslov. 75:226-42

69. Opit GP, Arthur FH, Bonjour EL, Jones CL, Phillips TW. 2011. Efficacy of heat treatment for disinfestation of concrete grain silos. 7. Econ. Entomol. 104:1415-22

70. Opit GP, Arthur FH, Throne JE, Payton ME. 2012. Susceptibility of stored-product psocids to aerosol insecticides. F. Insect Sci. 12(139):1-14

71. Opit GP, Throne JE. 2008. Effects of diet on population growth of the psocids Lepinotus reticulatus and Liposcelis entomophila. 7. Econ. Entomol. 101:616-22

72. Opit GP, Throne JE. 2009. Population growth and development of the psocid Liposcelis brunnea (Psocoptera: Liposcelididae) at constant temperatures and relative humidities. F. Econ. Entomol. 102:136068

73. Opit GP, Throne JE, Flinn PW. 2009. Evaluation of five sampling methods for the psocids Liposcelis entomophila and L. decolor (Psocoptera: Liposcelididae) in steel bins containing wheat. 7. Econ. Entomol. 102:1377-82

74. Opit GP, Throne JE, Flinn PW. 2009. Sampling plans for the psocids Liposcelis entomophila and Liposcelis decolor (Psocoptera: Liposcelididae) in steel bins containing wheat. 7. Econ. Entomol. 102:1714-22

75. Opit GP, Throne JE, Flinn PW. 2009. Temporospatial distribution of the psocids Liposcelis entomophila and L. decolor (Psocoptera: Liposcelididae) in steel bins containing wheat. F. Econ. Entomol. 102:1369-76

76. Pascual-Villalobos MJ, Baz A, Del Estal P. 2005. Occurrence of psocids and natural predators on organic rice in Calasparra (Murcia, Spain). 7. Stored Prod. Res. 41:231-35

77. Perlman SJ, Hunter MS, Zchori-Fein E. 2006. The emerging diversity of Rickettsia. Proc. R. Soc. B 273:2097-106

78. Perotti MA, Clarke HK, Turner BD, Braig HR. 2006. Rickettsia as obligate and mycetomic bacteria. FASEB 7. 20:2372

79. Phillips TW, Throne JE. 2010. Biorational approaches to managing stored-product insects. Annu. Rev. Entomol. 55:375-97

80. Pike V. 1994. Laboratory assessment of the efficacy of phosphine and methyl bromide fumigation against all life stages of Liposcelis entomophilus (Enderlein). Crop Prot. 13:141-45

81. Pike V, Rees D, Hatch R. 1991. Bionomics of Liposcelis paetus in stored grain (Psocoptera: Liposcelidae). In Proc. 5th Int. Working Conf. Stored Prod. Prot., ed. F Fleurat-Lessard, P Ducom, pp. 175-79. Bordeaux, Fr.: Impr. Médoc

82. Pranata RI, Haines CP, Roesli R, Sunjaya D. 1983. Dust admixture treatment with permethrin for the protection of rough rice and milled rice. In Proc. 6th Annual Grains Post-Harvest Workshop, ed. NC Teter, RL Semple, AS Frio, pp. 132-46. Bogor, Indones.: Puncak Pass

83. Qin M, Li Z, Kučerová Z, Cao Y, Stejskal V. 2008. Rapid discrimination of the common species of the stored product pest Liposcelis (Psocoptera: Liposcelididae) from China and the Czech Republic, based on PCR-RFLP analysis. Eur. 7. Entomol. 105:713-17

84. Rajendran S. 1994. Psocids in food commodities and their control. Pestology 28:14-19

85. Rees DP. 1998. Psocids as pests of Australian grain storages. In Stored Grain in Australia. Proceedings of the Australian Postharvest Technical Conference, ed. HJ Banks, EJ Wright, KA Damcevski, pp. 46-51. Canberra, Aust.: CSIRO Entomol.

86. Rees DP. 2003. Psocoptera (psocids) as pests of bulk grain storage in Australia: a cautionary tale to industry and researchers. In Advances in Stored Product Protection: Proc. 8th Int. Working Conf. Stored Prod. Prot., ed. PF Credland, DM Armitage, CH Bell, PM Cogan, E Highley, pp. 59-64. Wallingford, UK: CAB Int.
73. Evaluates psocid population monitoring devices including the development of sampling plans for IPM. 
92. Examines the factors and control methods associated with psocid infestations in large storage structures.

107. First systematic, detailed investigation of psocid life history.
87. Rees DP, Walker AJ. 1990. The effect of temperature and relative humidity on population growth of three Liposcelis species (Psocoptera: Liposcelidae) infesting stored products in tropical countries. Bull. Entomol. Res. 80:353-58

88. Riudavets J, Castañé C, Alomar O, Pons MJ, Gabarra R. 2009. Modified atmosphere packaging (MAP) as an alternative measure for controlling ten pests that attack processed food products. F. Stored Prod. Res. 45:91-96

89. Riudavets J, Lucas E, Pons MJ. 2002. Insects and mites of stored products in the northeast of Spain. IOBC Bull. 25:41-44

90. Roesli R, Jones R. 1994. The use of various insect traps for studying psocid populations. In Proc. 6th Int. Working Conf. Stored Prod. Prot., ed. E Highley, EJ Wright, HJ Banks, BR Champ, pp. 448-50. Wallingford, UK: CAB Int.

91. Roesli R, Jones R, Rees D. 1999. Factors affecting outbreaks of Liposcelis (Psocoptera: Liposcelidae) populations in grain storage. In Stored Product Protection: Proc. 7th Int. Working Conf. Stored Prod. Prot., ed. Z Jin, Q Liang, Y Liang, X Tan, L Guan, pp. 27-36. Chengdu, China: Sichuan Publ. House Sci. Technol.

92. Santoso T, Dharmaputra OS, Halid H, Hodges RJ. 1996. Pest management of psocids in milled rice stores in the humid tropics. Int. F. Pest Manage. 42:189-97

93. Sinha RN. 1988. Population dynamics of Psocoptera in farm-stored grain and oilseed. Can. 7. Zool. 66:2618-27

94. Smith LB. 1985. Insect infestation in grain loaded in railroad cars at primary elevators in Southern Manitoba, Canada. 7. Econ. Entomol. 78:531-34

95. Tang PA, Wang JJ, He Y, Jiang HB, Wang ZY. 2008. Development, survival, and reproduction of the psocid Liposcelis decolor (Psocoptera: Liposcelididae) at constant temperatures. Ann. Entomol. Soc. Am. 101:1017-25

96. Thepparit C, Sunyakumthorn P, Guillotte ML, Popov VL, Foil LD, Macaluso KR. 2011. Isolation of a rickettsial pathogen from a non-hematophagous arthropod. PLoS One 6:e16396

97. Trematerra P, Fiorilli F. 1999. Occurrence of arthropods in a central Italy feed-mill. Anz. Schädlingskunde 72:158-63

98. Turner BD. 1986. What's moving in the muesli? New Sci. 1513:43-45

99. Turner BD. 1987. Forming a clearer view of L. bostrychophilus. Environ. Health 95:9-13

100. Turner BD. 1994. Liposcelis bostrychophila (Psocoptera: Liposcelidae), a stored food pest in the UK. Int. 7. Pest Manage. 40:179-90

101. Turner B, Bishop J. 1998. What's bugging your kitchen? Environ. Health f. 106:310-14

102. Turner BD, Maude-Roxby H. 1988. Starvation survival of the stored product pest Liposcelis bostrychophilus (Badonnel) (Psocoptera, Liposcelidae). 7. Stored Prod. Res. 24:23-28

103. Turner BD, Maude-Roxby H, Pike V. 1991. Control of the domestic insect pest Liposcelis bostrychophila (Badonnel) (Psocoptera): an experimental evaluation of the efficiency of some insecticides. Int. Pest Control $33: 153-57$

104. Turner BD, Staines N, Brostoff J, Howe CA, Cooper K. 1996. Allergy to psocids. In Proc. 2nd Int. Conf. Insect Pests Urban Environ., ed. KB Wildey, p. 609. Edinburgh: BCP Wheatons

105. Wang JJ, Dong P, Xiao LS, Dou W. 2008. Effects of removal of Cardinium infection on fitness of the stored-product pest Liposcelis bostrychophila (Psocoptera: Liposcelididae). F. Econ. Entomol. 101:1711-17

106. Wang JJ, Ren Y, Wei XQ, Dou W. 2009. Development, survival, and reproduction of the psocid Liposcelis paeta (Psocoptera: Liposcelididae) as a function of temperature. F. Econ. Entomol. 102:1705-13

107. Wang JJ, Tsai JH, Zhao ZM, Li LS. 2000. Development and reproduction of the psocid Liposcelis bostrychophila (Psocoptera: Liposcelididae) as a function of temperature. Ann. Entomol. Soc. Am. 93:261-70

108. Wang JJ, Zhao ZM, Li LS. 1998. Studies on bionomics of Liposcelis entomophila (Psocoptera: Liposcelididae) infesting stored products. Entomol. Sin. 5:149-58

109. Wang JJ, Zhao ZM, Li LS. 1999. Induced tolerance of the psocid, Liposcelis bostrychophila Badonnel (Psocoptera: Liposcelididae), to controlled atmosphere. Int. F. Pest Manage. 45:75-79 
110. Wang JJ, Zhao ZM, Tsai JH. 2000. Resistance and some enzyme activities in Liposcelis bostrychophila (Badonnel) (Psocoptera: Liposcelididae) in relation to carbon dioxide enriched atmospheres. 7. Stored Prod. Res. 36:297-308

111. Wei DD, Shao R, Yuan ML, Dou W, Barker SC, Wang JJ. 2012. The multipartite mitochondrial genome of Liposcelis bostrychophila: insights into the evolution of mitochondrial genomes in bilateral animals. PLoS One 7:e33973

112. Wei DD, Yuan ML, Wang ZY, Wang D, Wang BJ, et al. 2011. Sequence analysis of the ribosomal internal transcribed spacers region in psocids (Psocoptera: Liposcelididae) for phylogenetic inference and species discrimination. 7. Econ. Entomol. 104:1720-29

113. Werren J, Windsor D. 2000. Wolbachia infection frequencies in insects: evidence of a global equilibrium? Proc. R. Soc. B. 267:1277-85

114. Wright EJ. 1990. A trapping method to evaluate efficacy of a structural treatment in empty silos. In Proc. 5th Int. Work. Conf. Stored Prod. Prot., ed. F Fleurat-Lesssard, P Ducum, pp. 1455-63. Bordeaux, Fr.: Impr. Médoc

115. Yang Q, Zhao S, Kučerová Z, Stejskal V, Opit G, et al. 2012. Validation of the 16S rDNA and COI DNA barcoding technique for rapid molecular identification of stored product psocids (Insecta: Psocodea: Liposcelididae). 7. Econ. Entomol. 106:419-25

116. Yao H, Song J, Liu C, Luo K, Han J, et al. 2010. Use of ITS2 region as the universal DNA barcode for plants and animals. PLoS One 5:e13102

117. Yusuf M, Turner B. 2004. Characterisation of Wolbachia-like bacteria isolated from the parthenogenetic stored-product pest psocid Liposcelis bostrychophila (Badonnel) (Psocoptera). F. Stored Prod. Res. 40:207-25

118. Yusuf M, Turner B, Whitfield P, Miles R, Pacey J. 2000. Electron microscopical evidence of a vertically transmitted Wolbachia-like parasite in the parthenogenetic, stored-product pest Liposcelis bostrychophila (Badonnel) (Psocoptera). 7. Stored Prod. Res. 36:169-75

\section{RELATED RESOURCES}

Johnson KP, Smith VS, Eades DC. 2013. Psocodea Species File Online. http://psocodea.speciesfile. org/

Kazunori Y. 2013. PsocoNet: The Psocidologists' Home Page. http://www.psocodea.org/

Lienhard C, Smithers CN. 2013. Psocoptera (Insecta) World Catalogue and Bibliography. http://www. ville-ge.ch/mhng/psocoptera/page/psocoptera.htm

Opit G, Throne J, Friesen K. 2012. Stored-Product Psocid Identification Website. http://www.ars. usda.gov/Services/docs.htm?docid=16769

115. Demonstrates the value of using molecular methods to identify psocid species. 
Supplemental Material: Annu. Rev. Entomol. 2014. 59:279-97

doi: 10.1146/annurev-ento-011613-161947

Biology and Management of Psocids Infesting Stored Products

Nayak et al.

Supplemental Table 1. Effects of temperature on duration of development of immature stages of Liposcelis spp. and Lepinotus reticulatus at 75 to $80 \%$ RH (over a saturated sodium chloride solution)

\begin{tabular}{|c|c|c|c|c|c|c|c|c|c|}
\hline \multirow{3}{*}{$\begin{array}{c}\text { Life stage/species } \\
\text { Egg }\end{array}$} & \multicolumn{9}{|c|}{ Duration of development (days $\pm \mathrm{SE}$ ) } \\
\hline & \multicolumn{9}{|c|}{ Temperature $\left({ }^{\circ} \mathrm{C}\right)$} \\
\hline & 20 & 22.5 & 25 & 27.5 & 30 & 32.5 & 35 & 37.5 & 40 \\
\hline L. badia & $24.3 \pm 0.4$ & $14.9 \pm 0.2$ & $12.7 \pm 0.2$ & $9.0 \pm 0.1$ & $7.8 \pm 0.2$ & $7.2 \pm 0.1$ & $7.4 \pm 0.2$ & $-^{c}$ & $-^{c}$ \\
\hline L. bostrychophila ${ }^{\mathrm{m}}$ & $13.8 \pm 0.9$ & $13.4 \pm 0.5$ & $12.6 \pm 0.2$ & $8.8 \pm 0.3$ & $8.2 \pm 0.2$ & $6.4 \pm 0.1$ & $7.6 \pm 0.3$ & $-c^{c}$ & $-^{c}$ \\
\hline L. brunnea females ${ }^{h}$ & $-c^{c}$ & $12.9 \pm 0.4$ & $9.9 \pm 0.3$ & $8.3 \pm 0.3$ & $6.6 \pm 0.3$ & $6.0 \pm 0.4$ & $6.3 \pm 0.5$ & $-^{c}$ & $-^{c}$ \\
\hline${\text { L. brunnea } \text { males }^{\mathrm{h}}}$ & $-^{c}$ & $14.1 \pm 0.4$ & $11.5 \pm 0.5$ & $9.4 \pm 0.5$ & $7.1 \pm 0.6$ & $7.3 \pm 0.5$ & $6.7 \pm 0.6$ & $-^{c}$ & $\mathrm{c}^{\mathrm{c}}$ \\
\hline L. decolor females ${ }^{i}$ & $14.1 \pm 0.2$ & $8.7 \pm 0.2$ & $8.2 \pm 0.2$ & $7.6 \pm 0.3$ & $5.7 \pm 0.1$ & $4.6 \pm 0.1$ & $4.8 \pm 0.2$ & $5.2 \pm 0.1$ & $-^{c}$ \\
\hline L. decolor males' & $15.1 \pm 0.3$ & $9.2 \pm 0.2$ & $8.9 \pm 0.2$ & $7.0 \pm 0.2$ & $6.2 \pm 0.2$ & $5.0 \pm 0.1$ & $4.7 \pm 0.1$ & $5.6 \pm 0.2$ & $-^{c}$ \\
\hline L. entomophila ${ }^{n}$ & $18.8 \pm 0.4$ & $13.8 \pm 0.5$ & $10.1 \pm 0.3$ & $7.9 \pm 0.1$ & $6.5 \pm 0.2$ & $5.4 \pm 0.4$ & $5.2 \pm 0.6$ & $-^{c}$ & $-^{c}$ \\
\hline L. paeta ${ }^{\mathrm{g}}$ & $-^{c}$ & $18.5 \pm 0.2$ & $13.7 \pm 0.2$ & $10.3 \pm 0.1$ & $8.9 \pm 0.1$ & $7.5 \pm 0.1$ & $6.7 \pm 0.1$ & $5.6 \pm 0.1$ & $-^{c}$ \\
\hline L. pearmani females ${ }^{a}$ & $-^{c}$ & $14.4 \pm 0.4$ & $10.0 \pm 0.3$ & $8.7 \pm 0.2$ & $6.9 \pm 0.1$ & $6.4 \pm 0.1$ & $6.5 \pm 0.2$ & $\mathrm{c}^{\mathrm{c}}$ & $\mathrm{c}^{\mathrm{c}}$ \\
\hline L. pearmani males ${ }^{a}$ & $-^{c}$ & $13.7 \pm 0.3$ & $10.3 \pm 0.3$ & $9.2 \pm 0.3$ & $8.0 \pm 0.4$ & $6.5 \pm 0.2$ & $7.2 \pm 0.3$ & $-^{c}$ & $-^{c}$ \\
\hline L. reticulatus ${ }^{\mathrm{k}}$ & $-^{c}$ & $11.9 \pm 0.4$ & $9.0 \pm 0.4$ & $7.4 \pm 0.4$ & $7.0 \pm 0.4$ & $6.4 \pm 0.4$ & $6.6 \pm 0.5$ & $-^{\mathrm{c}}$ & $-^{\mathrm{c}}$ \\
\hline L. rufa males ${ }^{f}$ & $\mathrm{c}^{\mathrm{c}}$ & $15.6 \pm 0.2$ & $11.6 \pm 0.2$ & $8.8 \pm 0.2$ & $7.5 \pm 0.2$ & $6.4 \pm 0.2$ & $5.1 \pm 0.2$ & $5.3 \pm 0.2$ & $5.8 \pm 0.3$ \\
\hline
\end{tabular}


Supplemental Material: Annu. Rev. Entomol. 2014. 59:279-97 doi: 10.1146/annurev-ento-011613-161947

Biology and Management of Psocids Infesting Stored Products Nayak et al.

\begin{tabular}{|c|c|c|c|c|c|c|c|c|c|}
\hline L. rufa females ${ }^{f}$ & $-{ }^{c}$ & $14.2 \pm 0.3$ & $10.2 \pm 0.2$ & $8.4 \pm 0.2$ & $6.7 \pm 0.2$ & $5.7 \pm 0.2$ & $5.1 \pm 0.2$ & $5.0 \pm 0.2$ & $4.5 \pm 0.5$ \\
\hline L. tricolor & 15.4 & 15.2 & 11.2 & 9.1 & 9.5 & 7.7 & 9.1 & $-{ }^{c}$ & $-{ }^{c}$ \\
\hline L. yunnaniensis $^{d}$ & $18.9 \pm 0.2$ & $12.6 \pm 0.1$ & $9.7 \pm 0.1$ & $8.1 \pm 0.1$ & $8.0 \pm 0.2$ & $8.3 \pm 0.1$ & $4.7 \pm 0.1$ & $4.3 \pm 0.1$ & - be \\
\hline \multicolumn{10}{|l|}{ Nymph (N) } \\
\hline L. badia & $21.8 \pm 0.5$ & $18.5 \pm 0.4$ & $17.0 \pm 0.3$ & $14.3 \pm 0.4$ & $12.0 \pm 0.5$ & $10.0 \pm 0.4$ & $11.9 \pm 0.6$ & $-{ }^{c}$ & $-{ }^{c}$ \\
\hline L. bostrychophila $^{\mathrm{m}}$ & $28.1 \pm 0.9$ & $24.7 \pm 0.3$ & $22.1 \pm 0.1$ & $15.6 \pm 0.4$ & $12.4 \pm 0.7$ & $11.6 \pm 0.3$ & $13.9 \pm 0.2$ & $-^{c}$ & $-{ }^{c}$ \\
\hline L. brunnea females ${ }^{h}$ & $-{ }^{c}$ & $36.7 \pm 1.6$ & $29.2 \pm 1.1$ & $28.6 \pm 1.1$ & $26.1 \pm 1.2$ & $24.4 \pm 1.5$ & $21.5 \pm 1.7$ & $-{ }^{c}$ & $-{ }^{c}$ \\
\hline L. brunnea males ${ }^{h}$ & $-{ }^{c}$ & $29.5 \pm 1.0$ & $22.9 \pm 1.1$ & $21.2 \pm 1.1$ & $18.7 \pm 1.5$ & $17.5 \pm 1.4$ & $18.4 \pm 1.5$ & $-{ }^{c}$ & $-{ }^{c}$ \\
\hline L. decolor females ${ }^{i}$ & $32.5 \pm 0.7$ & $23.0 \pm 0.5$ & $18.7 \pm 0.3$ & $15.2 \pm 0.4$ & $14.3 \pm 0.5$ & $11.6 \pm 0.2$ & $11.3 \pm 0.4$ & $14.8 \pm 0.5$ & $-{ }^{c}$ \\
\hline L. decolor males ${ }^{i}$ & $26.6 \pm 0.7$ & $19.7 \pm 0.6$ & $15.1 \pm 0.3$ & $13.7 \pm 0.4$ & $11.5 \pm 0.4$ & $8.9 \pm 0.2$ & $8.9 \pm 0.3$ & $10.7 \pm 0.6$ & $--^{c}$ \\
\hline L. entomophila ${ }^{\mathrm{n}}$ & $53.1 \pm 0.4$ & $43.8 \pm 0.4$ & $34.4 \pm 0.5$ & $27.1 \pm 0.1$ & $18.0 \pm 0.3$ & $17.7 \pm 0.4$ & $16.5 \pm 0.7$ & $-{ }^{c}$ & $-{ }^{c}$ \\
\hline L. paeta $^{\mathrm{g}}$ & $-{ }^{c}$ & $27.5 \pm 1.1$ & $18.8 \pm 0.3$ & $16.2 \pm 0.4$ & $13.7 \pm 0.3$ & $8.1 \pm 0.2$ & $7.8 \pm 0.2$ & $6.3 \pm 0.1$ & $-{ }^{c}$ \\
\hline L. pearmani females $^{a}$ & $-{ }^{c}$ & $35.5 \pm 1.2$ & $24.7 \pm 0.6$ & $19.0 \pm 0.6$ & $17.7 \pm 0.7$ & $15.4 \pm 0.5$ & $17.3 \pm 0.6$ & $-^{c}$ & $-^{c}$ \\
\hline L. pearmani males ${ }^{a}$ & $-{ }^{c}$ & $25.1 \pm 0.8$ & $17.9 \pm 0.4$ & $16.1 \pm 0.8$ & $13.9 \pm 1.2$ & $12.2 \pm 0.6$ & $14.4 \pm 0.9$ & $-{ }^{c}$ & $-{ }^{c}$ \\
\hline L. reticulatus ${ }^{\mathrm{k}}$ & $-{ }^{c}$ & $32.7 \pm 2.0$ & $25.3 \pm 2.0$ & $21.6 \pm 2.0$ & $19.3 \pm 2.0$ & $16.6 \pm 2.1$ & $16.8 \pm 2.9$ & $-{ }^{c}$ & $-{ }^{c}$ \\
\hline L. rufa females ${ }^{f}$ & $--^{c}$ & $33.2 \pm 0.9$ & $27.0 \pm 0.8$ & $21.1 \pm 0.8$ & $17.2 \pm 0.7$ & $15.9 \pm 0.9$ & $19.4 \pm 0.7$ & $16.6 \pm 0.8$ & $17.4 \pm 1.8$ \\
\hline
\end{tabular}


Supplemental Material: Annu. Rev. Entomol. 2014. 59:279-97 doi: 10.1146/annurev-ento-011613-161947

Biology and Management of Psocids Infesting Stored Products Nayak et al.

\begin{tabular}{|c|c|c|c|c|c|c|c|c|c|}
\hline L. rufa males ${ }^{f}$ & $-^{c}$ & $27.7 \pm 0.7$ & $21.1 \pm 0.6$ & $18.1 \pm 0.6$ & $13.1 \pm 0.6$ & $11.5 \pm 0.6$ & $12.7 \pm 0.7$ & $12.3 \pm 0.6$ & $14.2 \pm 0.9$ \\
\hline L. tricolor & 40.0 & 33.3 & 27.8 & 22.2 & 21.7 & 23.3 & 23.8 & $-^{\mathrm{c}}$ & $-^{c}$ \\
\hline L. yunnaniensis $^{d}$ & $45.4 \pm 1.9$ & $33.3 \pm 1.4$ & $28.0 \pm 0.9$ & $15.8 \pm 0.6$ & $17.6 \pm 0.7$ & $14.4 \pm 0.9$ & $11.5 \pm 0.3$ & $12.0 \pm 0.4$ & $-^{c}$ \\
\hline \multicolumn{10}{|l|}{ Egg to adult } \\
\hline L. badiaj & $46.5 \pm 0.6$ & $33.4 \pm 0.5$ & $29.7 \pm 0.3$ & $23.3 \pm 0.4$ & $19.8 \pm 0.5$ & $17.2 \pm 0.5$ & $19.3 \pm 0.6$ & $-b$ & $-^{c}$ \\
\hline L. bostrychophila $^{\mathrm{m}}$ & $41.9 \pm 1.0$ & $36.4 \pm 1.0$ & $34.8 \pm 0.3$ & $24.4 \pm 0.5$ & $21.0 \pm 0.2$ & $18.1 \pm 0.2$ & $21.5 \pm 0.1$ & $-^{c}$ & $-^{c}$ \\
\hline L. brunnea females ${ }^{h}$ & $-c^{c}$ & $49.6 \pm 1.6$ & $39.1 \pm 1.1$ & $36.8 \pm 1.1$ & $32.7 \pm 1.2$ & $30.5 \pm 1.5$ & $27.7 \pm 1.7$ & $-^{c}$ & $-c^{c}$ \\
\hline L. brunnea males ${ }^{\mathrm{h}}$ & $-^{c}$ & $43.7 \pm 1.0$ & $34.4 \pm 1.1$ & $30.6 \pm 1.1$ & $25.7 \pm 1.5$ & $24.6 \pm 1.4$ & $25.2 \pm 1.5$ & $-^{c}$ & $-^{c}$ \\
\hline L. decolor females ${ }^{i}$ & $46.2 \pm 0.6$ & $31.7 \pm 0.5$ & $26.9 \pm 0.3$ & $22.8 \pm 0.5$ & $20.0 \pm 0.5$ & $16.2 \pm 0.2$ & $16.1 \pm 0.4$ & $20.0 \pm 0.5$ & $-^{c}$ \\
\hline L. decolor males & $41.8 \pm 0.8$ & $28.9 \pm 0.6$ & $24.0 \pm 0.3$ & $20.7 \pm 0.4$ & $17.7 \pm 0.4$ & $14.0 \pm 0.2$ & $13.6 \pm 0.4$ & $16.3 \pm 0.6$ & $-^{c}$ \\
\hline L. entomophila ${ }^{\mathrm{n}}$ & $71.9 \pm 0.5$ & $57.6 \pm 0.4$ & $44.5 \pm 0.2$ & $35.0 \pm 0.1$ & $24.5 \pm 0.1$ & $23.1 \pm 0.1$ & $21.7 \pm 0.4$ & -c $^{c}$ & $-c^{c}$ \\
\hline L. paeta & $-c^{c}$ & $45.4 \pm 1.0$ & $32.2 \pm 0.4$ & $26.4 \pm 0.4$ & $22.5 \pm 0.3$ & $15.6 \pm 0.2$ & $14.2 \pm 0.2$ & $11.5 \pm 0.1$ & $-c^{c}$ \\
\hline L. pearmani females ${ }^{a}$ & $-^{c}$ & $49.2 \pm 1.0$ & $34.9 \pm 0.6$ & $26.8 \pm 1.0$ & $24.2 \pm 1.0$ & $21.9 \pm 0.5$ & $23.8 \pm 0.7$ & $-^{c}$ & $-^{c}$ \\
\hline L. pearmani males ${ }^{a}$ & $-^{c}$ & $38.8 \pm 0.9$ & $28.2 \pm 0.6$ & $25.3 \pm 0.7$ & $21.9 \pm 1.2$ & $18.7 \pm 0.7$ & $21.6 \pm 1.1$ & $-^{c}$ & $-^{c}$ \\
\hline L. reticulatus ${ }^{\mathrm{k}}$ & $-^{c}$ & $44.6 \pm 2.1$ & $34.3 \pm 2.1$ & $29.1 \pm 2.1$ & $26.3 \pm 2.1$ & $22.9 \pm 2.2$ & $23.4 \pm 3.0$ & $-^{c}$ & $-^{c}$ \\
\hline L. rufa females ${ }^{f}$ & $-^{\mathrm{c}}$ & $47.4 \pm 1.0$ & $37.3 \pm 0.9$ & $29.5 \pm 0.8$ & $24.5 \pm 0.7$ & $21.7 \pm 0.9$ & $24.6 \pm 0.8$ & $21.6 \pm 0.9$ & $22.0 \pm 1.9$ \\
\hline
\end{tabular}




\begin{tabular}{|c|c|c|c|c|c|c|c|c|c|}
\hline L. rufa males ${ }^{f}$ & $-^{c}$ & $43.4 \pm 0.7$ & $32.6 \pm 0.6$ & $26.9 \pm 0.6$ & $20.6 \pm 0.7$ & $17.8 \pm 0.6$ & $17.9 \pm 0.8$ & $17.5 \pm 0.6$ & $19.9 \pm 1.0$ \\
\hline L. tricolor & 57.1 & 47.6 & 38.5 & 31.7 & 32.2 & 32.2 & 32.0 & $-^{c}$ & $-^{c}$ \\
\hline L. yunnaniensis $^{d}$ & $64.3 \pm 1.9$ & $45.8 \pm 1.4$ & $37.8 \pm 0.8$ & $23.9 \pm 0.6$ & $25.6 \pm 0.7$ & $22.6 \pm 0.9$ & $16.1 \pm 0.3$ & $16.2 \pm 0.3$ & $-{ }^{c}$ \\
\hline
\end{tabular}

aDevelopment on cracked wheat (Aminatou BA, Gautam SG, Opit GP, Talley J, Shakya K. 2011. Population growth and development of Liposcelis pearmani (Psocoptera: Liposcelididae) at constant temperatures and relative humidities. Environ. Entomol. 40:788-96).

${ }^{b}$ No survivors at this temperature.

${ }^{\mathrm{C}}$ This temperature not tested.

${ }^{d}$ Development on a diet of whole wheat flour, skim milk, and yeast powder (10:1:1) (Hassan MW, Dou W, Chen L, Jiang H, Wang J. 2011. Development, survival, and reproduction of the psocid Liposcelis yunnaniensis (Psocoptera: Liposcelididae) at constant temperatures. J. Econ. Entomol. 104:1436-44).

${ }^{e}$ Eggs hatched at $39^{\circ} \mathrm{C}$, but not at $41^{\circ} \mathrm{C}$.

fDevelopment on cracked wheat (Gautam SG, Opit GP, Giles KL. 2010. Population growth and development of the psocid Liposcelis rufa (Psocoptera: Liposcelididae) at constant temperatures and relative humidities. J. Econ. Entomol. 103:1920-28).

${ }^{\mathrm{g}}$ Development on a diet of whole wheat flour, skim milk, and yeast powder (10:1:1) (Wang JJ, Ren Y, Wei XQ, Dou W. 2009. Development, survival, and reproduction of the psocid Liposcelis paeta (Psocoptera: Liposcelididae) as a function of temperature. J. Econ. Entomol. 102:1705-13).

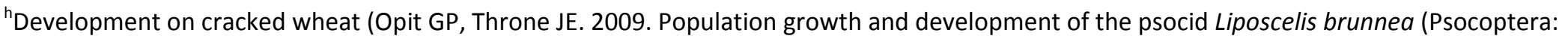
Liposcelididae) at constant temperatures and relative humidities. J. Econ. Entomol. 102:1360-68).

'Development on a diet of whole wheat flour, skim milk, and yeast powder (10:1:1) (Tang PA, Wang JJ, He Y, Jiang HB, Wang ZY. 2008. Development, survival, and reproduction of the psocid Liposcelis decolor (Psocoptera: Liposcelididae) at constant temperatures. Ann. Entomol. Soc. Am. 101:1017-25).

'Development on a diet of whole wheat flour, skim milk, and yeast powder (10:1:1) (Jiang H, Liu J, Wang Z, Wang J. 2008. Temperature-dependent 
Biology and Management of Psocids Infesting Stored Products

Nayak et al.

development and reproduction of a novel stored product psocid, Liposcelis badia (Psocoptera: Liposcelididae). Environ. Entomol. 37:1105-12).

${ }^{k}$ Development on cracked wheat (Opit GP, Throne JE. 2008. Population growth and development of the psocids Lepinotus reticulatus at constant temperatures and relative humidities. J. Econ. Entomol. 101:605-15).

'Development (days estimated from graph in manuscript) on a diet of whole wheat flour, skim milk, and yeast powder (10:1:1) (Dong P, Wang JJ, Hu F, Jia FX, Hu F. 2007. Development and reproduction of the psocid Liposcelis tricolor (Psocoptera: Liposcelididae) as a function of temperature. J. Econ. Entomol. 100:228-35).

m Development on a diet of whole wheat flour, skim milk, and yeast powder (10:1:1) (Wang JJ, Tsai JH, Zhao ZM, Li LS. 2000. Development and reproduction of the psocid Liposcelis bostrychophila (Psocoptera: Liposcelididae) as a function of temperature. Ann. Entomol. Soc. Am. 93:261-70).

${ }^{n}$ Development on a diet of whole wheat flour and yeast powder (10:1) (Wang J, Zhao Z, Li L. 1998. Studies on bionomics of Liposcelis entomophila (Psocoptera: Liposcelididae) infesting stored products. Entomol. Sinica 5:149-58). Development time of eggs at $17.5^{\circ} \mathrm{C}$ and $75 \%$ RH was $27.2 \pm 0.6$ days, and was $8.1 \pm 0.5,8.0 \pm 0.3,7.3 \pm 0.1$, and $6.8 \pm 0.5$ days at $28^{\circ} \mathrm{C}$ and $60,70,80$, and $90 \% \mathrm{RH}$, respectively. Development time of nymphs was $26.3 \pm 1.2,22.0 \pm$ $0.7,21.2 \pm 0.1$, and $16.2 \pm 0.3$ days at $28^{\circ} \mathrm{C}$ and $60,70,80$, and $90 \% \mathrm{RH}$, respectively, and development time from egg to adult was $34.4 \pm 0.7,30.0 \pm 0.5$, $28.5 \pm 0.1$, and $23.0 \pm 0.4$ days at $28^{\circ} \mathrm{C}$ and $60,70,80$, and $90 \% \mathrm{RH}$, respectively. 
Supplemental Material: Annu. Rev. Entomol. 2014. 59:279-97

doi: 10.1146/annurev-ento-011613-161947

Biology and Management of Psocids Infesting Stored Products

Nayak et al.

Supplemental Table 2. Effects of temperature on duration of development of nymphal instars of Liposcelis spp. and Lepinotus reticulatus at 75 to $80 \% \mathrm{RH}$ (over a saturated sodium chloride solution)

\begin{tabular}{|c|c|c|c|c|c|c|c|c|c|}
\hline \multirow{2}{*}{ Instar/species } & \multicolumn{9}{|c|}{ Duration of development (days \pm SE) } \\
\hline & \multicolumn{9}{|c|}{ Temperature $\left({ }^{\circ} \mathrm{C}\right)$} \\
\hline Nymph 1 & 20 & 22.5 & 25 & 27.5 & 30 & 32.5 & 35 & 37.5 & 40 \\
\hline L. badia ${ }^{\mathrm{h}}$ & $8.3 \pm 0.5$ & $7.1 \pm 0.3$ & $6.8 \pm 0.2$ & $5.9 \pm 0.3$ & $4.1 \pm 0.3$ & $2.9 \pm 0.2$ & $3.7 \pm 0.3$ & $-{ }^{c}$ & $-{ }^{c}$ \\
\hline L. bostrychophila ${ }^{\mathrm{k}}$ & $8.0 \pm 1.0$ & $7.4 \pm 0.1$ & $7.1 \pm 0.7$ & $5.9 \pm 0.3$ & $3.3 \pm 0.3$ & $2.7 \pm 0.2$ & $3.3 \pm 0.1$ & $-{ }^{c}$ & $-^{c}$ \\
\hline L. brunnea females ${ }^{f}$ & $-{ }^{c}$ & $11.6 \pm 0.7$ & $8.6 \pm 0.5$ & $8.2 \pm 0.5$ & $7.3 \pm 0.6$ & $6.5 \pm 0.7$ & $6.1 \pm 0.7$ & $-{ }^{c}$ & $-^{c}$ \\
\hline L. brunnea males ${ }^{\dagger}$ & $-{ }^{c}$ & $10.9 \pm 0.5$ & $9.0 \pm 0.6$ & $8.3 \pm 0.6$ & $6.2 \pm 0.8$ & $6.8 \pm 0.7$ & $5.1 \pm 0.8$ & $-^{c}$ & $-^{c}$ \\
\hline L. decolor females ${ }^{\mathrm{g}}$ & $9.5 \pm 0.3$ & $8.3 \pm 0.3$ & $6.3 \pm 0.3$ & $4.9 \pm 0.1$ & $3.8 \pm 0.2$ & $3.6 \pm 0.1$ & $2.8 \pm 0.2$ & $4.7 \pm 0.2$ & $-^{c}$ \\
\hline L. decolor males ${ }^{\mathrm{g}}$ & $10.3 \pm 0.3$ & $8.1 \pm 0.3$ & $6.4 \pm 0.3$ & $6.0 \pm 0.3$ & $3.6 \pm 0.2$ & $3.4 \pm 0.2$ & $3.1 \pm 0.2$ & $4.2 \pm 0.4$ & $-^{c}$ \\
\hline L. paeta ${ }^{\mathrm{e}}$ & $-{ }^{c}$ & $5.1 \pm 0.3$ & $5.2 \pm 0.3$ & $3.2 \pm 0.2$ & $4.0 \pm 0.2$ & $2.8 \pm 0.1$ & $2.0 \pm 0.1$ & $2.3 \pm 0.1$ & $-^{c}$ \\
\hline L. pearmani females $^{a}$ & $-^{c}$ & $9.2 \pm 0.4$ & $6.4 \pm 0.3$ & $6.2 \pm 0.2$ & $5.0 \pm 0.2$ & $5.0 \pm 0.3$ & $4.5 \pm 0.3$ & $-^{c}$ & $-^{c}$ \\
\hline L. pearmani males ${ }^{a}$ & $-{ }^{c}$ & $9.7 \pm 0.8$ & $5.7 \pm 0.3$ & $6.3 \pm 0.4$ & $4.9 \pm 0.3$ & $4.4 \pm 0.3$ & $4.8 \pm 0.5$ & $-^{c}$ & $-^{c}$ \\
\hline L. reticulatus & $-{ }^{c}$ & $8.7 \pm 0.5$ & $6.5 \pm 0.6$ & $5.7 \pm 0.7$ & $4.5 \pm 0.6$ & $4.1 \pm 0.7$ & $3.8 \pm 1.3$ & $-^{c}$ & $-^{c}$ \\
\hline L. rufa females ${ }^{d}$ & $-{ }^{c}$ & $10.0 \pm 0.3$ & $7.6 \pm 0.3$ & $6.4 \pm 0.3$ & $5.8 \pm 0.2$ & $5.2 \pm 0.3$ & $6.1 \pm 0.3$ & $5.9 \pm 0.3$ & $5.3 \pm 0.6$ \\
\hline
\end{tabular}


Supplemental Material: Annu. Rev. Entomol. 2014. 59:279-97 doi: 10.1146/annurev-ento-011613-161947

Biology and Management of Psocids Infesting Stored Products Nayak et al.

\begin{tabular}{|c|c|c|c|c|c|c|c|c|c|}
\hline L. rufa males $^{d}$ & $-^{c}$ & $7.9 \pm 0.3$ & $7.8 \pm 0.2$ & $6.3 \pm 0.2$ & $5.8 \pm 0.2$ & $4.9 \pm 0.2$ & $5.9 \pm 0.3$ & $5.8 \pm 0.2$ & $5.3 \pm 0.4$ \\
\hline L. tricolor & 11.1 & 9.1 & 7.7 & 6.3 & 6.1 & 6.9 & 7.1 & $-{ }^{c}$ & $-{ }^{c}$ \\
\hline \multicolumn{10}{|l|}{ Nymph 2} \\
\hline L. badia ${ }^{\mathrm{h}}$ & $7.2 \pm 0.4$ & $5.6 \pm 0.2$ & $5.1 \pm 0.2$ & $4.1 \pm 0.2$ & $3.8 \pm 0.3$ & $3.5 \pm 0.2$ & $4.0 \pm 0.3$ & $-{ }^{c}$ & $-^{c}$ \\
\hline L. bostrychophila ${ }^{\mathrm{k}}$ & $6.9 \pm 0.2$ & $5.3 \pm 0.1$ & $5.0 \pm 0.4$ & $3.6 \pm 0.4$ & $3.7 \pm 0.1$ & $3.8 \pm 0.1$ & $4.3 \pm 0.2$ & $-{ }^{c}$ & $-^{c}$ \\
\hline L. brunnea females ${ }^{f}$ & $-{ }^{c}$ & $6.8 \pm 0.5$ & $5.7 \pm 0.3$ & $6.1 \pm 0.3$ & $5.9 \pm 0.4$ & $5.9 \pm 0.5$ & $4.6 \pm 0.5$ & $-{ }^{c}$ & $--^{c}$ \\
\hline L. brunnea males ${ }^{f}$ & $-{ }^{c}$ & $8.1 \pm 0.3$ & $5.7 \pm 0.4$ & $6.0 \pm 0.4$ & $6.1 \pm 0.5$ & $4.8 \pm 0.4$ & $5.5 \pm 0.5$ & $-{ }^{c}$ & $-{ }^{c}$ \\
\hline L. decolor females ${ }^{g}$ & $7.2 \pm 0.4$ & $5.1 \pm 0.3$ & $4.8 \pm 0.2$ & $3.9 \pm 0.2$ & $3.8 \pm 0.2$ & $2.9 \pm 0.1$ & $2.7 \pm 0.1$ & $3.5 \pm 0.2$ & $-{ }^{c}$ \\
\hline L. decolor males ${ }^{\mathrm{g}}$ & $8.0 \pm 0.5$ & $6.2 \pm 0.4$ & $4.7 \pm 0.2$ & $4.3 \pm 0.3$ & $3.9 \pm 0.2$ & $2.9 \pm 0.2$ & $2.9 \pm 0.2$ & $3.3 \pm 0.2$ & $-^{c}$ \\
\hline L. paeta & $-{ }^{c}$ & $7.0 \pm 0.4$ & $4.4 \pm 0.2$ & $3.3 \pm 0.2$ & $3.5 \pm 0.2$ & $2.6 \pm 0.1$ & $1.9 \pm 0.1$ & $1.7 \pm 0.1$ & $-{ }^{c}$ \\
\hline L. pearmani females ${ }^{a}$ & $-{ }^{c}$ & $7.4 \pm 0.5$ & $5.4 \pm 0.3$ & $5.4 \pm 0.3$ & $5.0 \pm 0.4$ & $4.6 \pm 0.2$ & $4.7 \pm 0.4$ & $-{ }^{c}$ & $-{ }^{c}$ \\
\hline L. pearmani males ${ }^{\mathrm{a}}$ & $-{ }^{c}$ & $7.4 \pm 0.5$ & $5.8 \pm 0.3$ & $5.7 \pm 0.5$ & $4.4 \pm 0.5$ & $4.5 \pm 0.4$ & $4.7 \pm 0.4$ & $-{ }^{c}$ & $-{ }^{c}$ \\
\hline L. reticulatus ${ }^{i}$ & $-{ }^{c}$ & $8.7 \pm 0.6$ & $6.1 \pm 0.7$ & $3.5 \pm 0.8$ & $3.8 \pm 0.8$ & $4.4 \pm 0.8$ & $4.5 \pm 1.8$ & $-{ }^{c}$ & $-^{c}$ \\
\hline L. rufa females ${ }^{d}$ & $-{ }^{c}$ & $6.8 \pm 0.4$ & $6.0 \pm 0.3$ & $5.5 \pm 0.3$ & $4.3 \pm 0.3$ & $4.6 \pm 0.4$ & $5.8 \pm 0.3$ & $4.3 \pm 0.3$ & $4.9 \pm 0.7$ \\
\hline L. rufa males ${ }^{d}$ & $-{ }^{c}$ & $7.3 \pm 0.4$ & $6.1 \pm 0.3$ & $5.8 \pm 0.3$ & $4.5 \pm 0.3$ & $4.8 \pm 0.3$ & $5.1 \pm 0.4$ & $4.5 \pm 0.3$ & $4.3 \pm 0.5$ \\
\hline L. tricolor ${ }^{j}$ & 11.1 & 10.5 & 7.1 & 5.6 & 5.9 & 6.3 & 6.4 & $-{ }^{c}$ & $-{ }^{c}$ \\
\hline
\end{tabular}


Supplemental Material: Annu. Rev. Entomol. 2014. 59:279-97 doi: 10.1146/annurev-ento-011613-161947

Biology and Management of Psocids Infesting Stored Products

Nayak et al.

\begin{tabular}{|c|c|c|c|c|c|c|c|c|c|}
\hline Nymph 3 & & & & & & & & & \\
\hline L. badia ${ }^{\mathrm{h}}$ & $6.3 \pm 0.4$ & $5.8 \pm 0.3$ & $5.1 \pm 0.2$ & $4.3 \pm 0.2$ & $4.1 \pm 0.3$ & $3.6 \pm 0.2$ & $4.2 \pm 0.4$ & $-{ }^{c}$ & $-{ }^{c}$ \\
\hline L. bostrychophila & $6.2 \pm 0.2$ & $5.7 \pm 0.3$ & $4.7 \pm 0.4$ & $3.6 \pm 0.5$ & $3.0 \pm 0.1$ & $2.8 \pm 0.1$ & $3.2 \pm 0.2$ & $-{ }^{c}$ & $-{ }^{c}$ \\
\hline L. brunnea females ${ }^{f}$ & $-{ }^{c}$ & $7.6 \pm 0.6$ & $7.2 \pm 0.4$ & $6.7 \pm 0.4$ & $6.4 \pm 0.4$ & $5.8 \pm 0.6$ & $4.3 \pm 0.7$ & $-{ }^{c}$ & $-{ }^{c}$ \\
\hline L. brunnea males ${ }^{f}$ & $-{ }^{c}$ & $10.6 \pm 0.6$ & $8.1 \pm 0.7$ & $6.9 \pm 0.7$ & $6.3 \pm 0.9$ & $6.0 \pm 0.8$ & $7.8 \pm 0.9$ & $-{ }^{c}$ & $-^{c}$ \\
\hline L. decolor females ${ }^{g}$ & $7.7 \pm 0.4$ & $4.8 \pm 0.2$ & $3.7 \pm 0.2$ & $3.3 \pm 0.2$ & $3.6 \pm 0.2$ & $3.0 \pm 0.1$ & $2.9 \pm 0.2$ & $3.4 \pm 0.2$ & $-^{c}$ \\
\hline L. decolor males ${ }^{g}$ & $8.3 \pm 0.3$ & $5.5 \pm 0.3$ & $4.0 \pm 0.2$ & $3.5 \pm 0.2$ & $3.9 \pm 0.2$ & $2.7 \pm 0.1$ & $2.9 \pm 0.2$ & $3.2 \pm 0.3$ & $--^{c}$ \\
\hline L. paeta ${ }^{\mathrm{e}}$ & $-{ }^{c}$ & $7.6 \pm 0.5$ & $5.5 \pm 0.3$ & $3.9 \pm 0.3$ & $3.9 \pm 0.2$ & $2.6 \pm 0.1$ & $2.0 \pm 0.1$ & $1.4 \pm 0.1$ & $-^{c}$ \\
\hline L. pearmani females ${ }^{a}$ & $-{ }^{c}$ & $8.3 \pm 0.4$ & $6.5 \pm 0.5$ & $5.6 \pm 0.3$ & $5.1 \pm 0.4$ & $4.3 \pm 0.3$ & $4.7 \pm 0.3$ & $-{ }^{c}$ & $-^{c}$ \\
\hline L. pearmani males ${ }^{a}$ & $-{ }^{c}$ & $8.1 \pm 0.6$ & $6.2 \pm 0.4$ & $5.0 \pm 0.5$ & $4.9 \pm 0.7$ & $3.7 \pm 0.3$ & $3.8 \pm 0.2$ & $--^{c}$ & $-^{c}$ \\
\hline L. reticulatus ${ }^{i}$ & $-{ }^{c}$ & $9.1 \pm 0.8$ & $7.0 \pm 0.9$ & $5.4 \pm 0.9$ & $5.5 \pm 0.9$ & $4.2 \pm 0.9$ & $5.5 \pm 1.8$ & $-{ }^{c}$ & $-{ }^{c}$ \\
\hline L. rufa females ${ }^{d}$ & $-{ }^{c}$ & $7.1 \pm 0.4$ & $6.4 \pm 0.3$ & $5.0 \pm 0.3$ & $4.7 \pm 0.3$ & $4.6 \pm 0.4$ & $5.2 \pm 0.3$ & $4.9 \pm 0.4$ & $3.5 \pm 0.8$ \\
\hline L. rufa males ${ }^{d}$ & $-{ }^{c}$ & $7.2 \pm 0.3$ & $5.7 \pm 0.3$ & $5.4 \pm 0.3$ & $4.0 \pm 0.4$ & $5.0 \pm 0.5$ & $3.4 \pm 0.7$ & $3.8 \pm 0.4$ & $4.5 \pm 0.5$ \\
\hline L. tricolor & 10.0 & 8.0 & 6.7 & 5.7 & 4.2 & 4.5 & 5.0 & $-{ }^{c}$ & $-^{c}$ \\
\hline \multicolumn{10}{|l|}{ Nymph 4} \\
\hline L. bostrychophila & $7.1 \pm 0.3$ & $6.2 \pm 0.1$ & $5.4 \pm 0.8$ & $2.5 \pm 0.6$ & $2.4 \pm 0.3$ & $2.3 \pm 0.2$ & $3.1 \pm 0.3$ & $-{ }^{c}$ & $-^{c}$ \\
\hline
\end{tabular}


Supplemental Material: Annu. Rev. Entomol. 2014. 59:279-97

doi: 10.1146/annurev-ento-011613-161947

Biology and Management of Psocids Infesting Stored Products

Nayak et al.

\begin{tabular}{|c|c|c|c|c|c|c|c|c|c|}
\hline L. brunnea females ${ }^{f}$ & $-^{c}$ & $10.8 \pm 1.0$ & $7.5 \pm 0.8$ & $7.5 \pm 0.8$ & $6.3 \pm 0.8$ & $5.7 \pm 1.0$ & $6.6 \pm 1.1$ & $-^{c}$ & $-^{c}$ \\
\hline L. decolor females ${ }^{g}$ & $7.7 \pm 0.4$ & $4.8 \pm 0.2$ & $3.8 \pm 0.2$ & $3.1 \pm 0.2$ & $3.1 \pm 0.2$ & $2.6 \pm 0.1$ & $2.9 \pm 0.2$ & $3.7 \pm 0.1$ & $-^{c}$ \\
\hline L. paeta ${ }^{\mathrm{e}}$ & $-^{c}$ & $8.3 \pm 0.8$ & $5.2 \pm 0.4$ & $5.0 \pm 0.3$ & $3.6 \pm 0.3$ & $2.8 \pm 0.2$ & $2.5 \pm 0.2$ & $1.3 \pm 0.2$ & $\mathrm{-c}^{\mathrm{c}}$ \\
\hline L. pearmani females ${ }^{a}$ & $--^{c}$ & $9.9 \pm 0.7$ & $8.0 \pm 0.5$ & $5.6 \pm 0.4$ & $6.0 \pm 0.5$ & $4.1 \pm 0.4$ & $5.1 \pm 0.6$ & $-^{c}$ & $-{ }^{c}$ \\
\hline L. reticulatus ${ }^{i}$ & $-^{c}$ & $9.8 \pm 1.1$ & $9.2 \pm 1.3$ & $6.0 \pm 1.4$ & $8.2 \pm 1.3$ & $4.7 \pm 1.4$ & $4.3 \pm 2.8$ & $-^{c}$ & $-^{c}$ \\
\hline L. rufa females ${ }^{d}$ & $-^{\mathrm{c}}$ & $7.4 \pm 0.5$ & $6.4 \pm 0.4$ & $5.6 \pm 0.5$ & $5.3 \pm 0.6$ & $4.7 \pm 0.9$ & $5.8 \pm 0.6$ & $4.7 \pm 0.9$ & $4.8 \pm 1.0$ \\
\hline L. tricolor & 10.0 & 8.3 & 6.5 & 4.5 & 5.1 & 4.4 & 5.6 & $-{ }^{c}$ & $-^{\mathrm{c}}$ \\
\hline
\end{tabular}

${ }^{a}$ Development on cracked wheat (Aminatou et al. 2011, refer to Supplemental Table 1).

${ }^{\mathrm{b}}$ No survivors at this temperature.

${ }^{\mathrm{c}}$ This temperature not tested.

${ }^{\mathrm{d}}$ Development on cracked wheat (Gautam et al. 2010, refer to Supplemental Table 1).

${ }^{\mathrm{e}}$ Development on a diet of whole wheat flour, skim milk, and yeast powder (10:1:1) (Wang et al. 2009, refer to Supplemental Table 1).

fDevelopment on cracked wheat (Opit and Throne 2009, refer to Supplemental Table 1).

${ }^{g}$ Development on a diet of whole wheat flour, skim milk, and yeast powder (10:1:1) (Tang et al. 2008, refer to Supplemental Table 1).

${ }^{h}$ Development on a diet of whole wheat flour, skim milk, and yeast powder (10:1:1) (Jiang et al. 2008, refer to Supplemental Table 1).

'Development on cracked wheat (Opit and Throne 2008, refer to Supplemental Table 1). 
Supplemental Material: Annu. Rev. Entomol. 2014. 59:279-97

doi: 10.1146/annurev-ento-011613-161947

Biology and Management of Psocids Infesting Stored Products

Nayak et al.

'Development (days estimated from graph in manuscript) on a diet of whole wheat flour, skim milk, and yeast powder (10:1:1) (Dong et al. 2007, refer to Supplemental Table 1).

${ }^{k}$ Development on a diet of whole wheat flour, skim milk, and yeast powder (10:1:1) (Wang et al. 2000, refer to Supplemental Table 1). 
Supplemental Material: Annu. Rev. Entomol. 2014. 59:279-97

doi: 10.1146/annurev-ento-011613-161947

Biology and Management of Psocids Infesting Stored Products

Nayak et al.

Supplemental Table 3. Effects of temperature on immature survivorship of Liposcelis spp. at 75 to $80 \%$ RH (over a saturated sodium chloride solution)

\begin{tabular}{|c|c|c|c|c|c|c|c|c|c|}
\hline \multirow{3}{*}{$\begin{array}{c}\text { Life stage/species } \\
\text { Egg }\end{array}$} & \multicolumn{9}{|c|}{ Immature survivorship (\% $\pm \mathrm{SE}$ ) } \\
\hline & \multicolumn{9}{|c|}{ Temperature $\left({ }^{\circ} \mathrm{C}\right)$} \\
\hline & 20 & 22.5 & 25 & 27.5 & 30 & 32.5 & 35 & 37.5 & 40 \\
\hline L. badia ${ }^{\mathrm{g}}$ & $69.9 \pm 6.8$ & $83.1 \pm 5.9$ & $89.5 \pm 2.2$ & $80.6 \pm 5.2$ & $56.7 \pm 5.3$ & $81.8 \pm 1.4$ & $54.5 \pm 8.0$ & $-{ }^{b}$ & $-{ }^{b}$ \\
\hline L. bostrychophila & $59.3 \pm 3.1$ & $69.1 \pm 2.0$ & $74.2 \pm 0.7$ & $92.6 \pm 0.2$ & $88.3 \pm 0.5$ & $78.4 \pm 0.8$ & $71.7 \pm 1.1$ & $-{ }^{b}$ & $-{ }^{b}$ \\
\hline L. decolor ${ }^{f}$ & $84.2 \pm 1.9$ & $86.5 \pm 0.7$ & $89.0 \pm 1.3$ & $90.6 \pm 1.7$ & $93.5 \pm 1.1$ & $89.4 \pm 1.4$ & $82.6 \pm 0.5$ & $67.2 \pm 1.2$ & $-{ }^{b}$ \\
\hline L. entomophila & $72.1 \pm 1.2$ & $78.9 \pm 0.4$ & $79.3 \pm 0.3$ & $73.3 \pm 0.7$ & $73.3 \pm 0.7$ & $67.8 \pm 0.9$ & $63.3 \pm 0.7$ & $-{ }^{b}$ & $-b$ \\
\hline L. paeta $^{d}$ & $-{ }^{b}$ & $52.0 \pm 0.0$ & $69.6 \pm 0.1$ & $67.3 \pm 0.0$ & $58.4 \pm 0.1$ & $77.3 \pm 0.1$ & $55.5 \pm 0.1$ & $65.0 \pm 0.0$ & $-{ }^{b}$ \\
\hline L. yunnaniensis $^{a}$ & $60.5 \pm 8.2$ & $69.2 \pm 5.2$ & $78.9 \pm 2.9$ & $63.0 \pm 1.3$ & $65.1 \pm 9.3$ & $57.9 \pm 5.2$ & $70.7 \pm 3.3$ & $76.0 \pm 2.9$ & $0.0 \pm 0.0$ \\
\hline \multicolumn{10}{|l|}{ Nymph 1 (N1) } \\
\hline L. badia $^{\mathrm{g}}$ & $32.8 \pm 3.9$ & $40.8 \pm 5.7$ & $64.3 \pm 4.6$ & $66.3 \pm 0.0$ & $60.8 \pm 2.3$ & $55.6 \pm 2.4$ & $38.2 \pm 1.4$ & $-{ }^{b}$ & $-{ }^{b}$ \\
\hline L. bostrychophilai & $76.7 \pm 1.0$ & $87.3 \pm 2.5$ & $90.9 \pm 0.5$ & $92.5 \pm 0.2$ & $93.5 \pm 0.4$ & $89.2 \pm 1.1$ & $80.0 \pm 1.1$ & $-{ }^{b}$ & $-{ }^{b}$ \\
\hline L. paeta $\mathrm{N} 1^{\mathrm{d}}$ & $-{ }^{b}$ & $52.8 \pm 0.1$ & $68.9 \pm 0.0$ & $68.3 \pm 0.0$ & $66.7 \pm 0.0$ & $79.2 \pm 0.1$ & $66.5 \pm 0.0$ & $68.6 \pm 0.0$ & $-{ }^{b}$ \\
\hline \multicolumn{10}{|l|}{ Nymph 2 (N2) } \\
\hline L. badia ${ }^{\mathrm{g}}$ & $90.5 \pm 1.5$ & $84.7 \pm 5.9$ & $80.1 \pm 2.6$ & $96.9 \pm 1.8$ & $87.9 \pm 7.8$ & $76.0 \pm 5.2$ & $87.4 \pm 3.1$ & $-{ }^{b}$ & $-{ }^{b}$ \\
\hline
\end{tabular}


Supplemental Material: Annu. Rev. Entomol. 2014. 59:279-97 doi: 10.1146/annurev-ento-011613-161947

Biology and Management of Psocids Infesting Stored Products Nayak et al.

\begin{tabular}{|c|c|c|c|c|c|c|c|c|c|}
\hline L. bostrychophilai & $91.7 \pm 0.9$ & $92.2 \pm 1.0$ & $93.3 \pm 0.7$ & $96.8 \pm 0.1$ & $98.2 \pm 0.1$ & $96.2 \pm 0.8$ & $94.7 \pm 0.7$ & $-{ }^{b}$ & $-b$ \\
\hline L. paeta $\mathrm{N} 2^{\mathrm{d}}$ & $-b$ & $88.7 \pm 0.1$ & $95.5 \pm 0.0$ & $91.8 \pm 0.0$ & $90.2 \pm 0.1$ & $91.9 \pm 0.1$ & $93.7 \pm 0.0$ & $68.6 \pm 0.0$ & $-b$ \\
\hline \multicolumn{10}{|l|}{ Nymph 3 (N3) } \\
\hline L. badia ${ }^{\mathrm{g}}$ & $97.2 \pm 2.8$ & $93.4 \pm 4.6$ & $94.7 \pm 0.0$ & $93.2 \pm 5.8$ & $90.3 \pm 4.3$ & $88.9 \pm 2.9$ & $100 \pm 0.0$ & $-b^{b}$ & $-b$ \\
\hline L. bostrychophila & $96.3 \pm 0.3$ & $96.3 \pm 0.3$ & $96.3 \pm 0.2$ & $100 \pm 0.0$ & $100 \pm 0.0$ & $95.9 \pm 1.0$ & $95.4 \pm 1.0$ & $-{ }^{b}$ & $-{ }^{b}$ \\
\hline L. paeta N3 ${ }^{d}$ & $-{ }^{b}$ & $84.9 \pm 0.1$ & $99.0 \pm 0.0$ & $94.9 \pm 0.0$ & $99.1 \pm 0.0$ & $94.9 \pm 0.0$ & $97.4 \pm 0.0$ & $98.5 \pm 0.0$ & $-{ }^{b}$ \\
\hline \multicolumn{10}{|l|}{ Nymph 4 (N4) } \\
\hline L. bostrychophila & $93.1 \pm 0.5$ & $98.2 \pm 0.1$ & $100 \pm 0.0$ & $100 \pm 0.0$ & $100 \pm 0.0$ & $100 \pm 0.0$ & $96.7 \pm 0.2$ & $-{ }^{b}$ & $-{ }^{b}$ \\
\hline L. paeta $\mathrm{N} 4^{\mathrm{d}}$ & $-{ }^{b}$ & $98.7 \pm 0.0$ & 100.0 & 100.0 & 100.0 & 100.0 & $99.2 \pm 0.0$ & $99.2 \pm 0.0$ & $-{ }^{b}$ \\
\hline \multicolumn{10}{|l|}{ Nymph } \\
\hline L. badia $^{\mathrm{g}}$ & $28.7 \pm 2.9$ & $32.4 \pm 5.8$ & $48.5 \pm 1.6$ & $59.9 \pm 0.0$ & $48.4 \pm 5.5$ & $37.3 \pm 1.5$ & $33.3 \pm 1.4$ & $-b$ & $-{ }^{b}$ \\
\hline L. bostrychophila & $63.0 \pm 1.5$ & $76.2 \pm 1.3$ & $81.7 \pm 1.0$ & $89.6 \pm 0.8$ & $91.9 \pm 0.6$ & $82.3 \pm 1.2$ & $69.8 \pm 1.6$ & $-b$ & $-{ }^{b}$ \\
\hline L. brunnea & $-{ }^{c}$ & 0.82 & 0.78 & 0.75 & 0.62 & 0.48 & 0.38 & $-{ }^{c}$ & $-^{c}$ \\
\hline L. decolor ${ }^{f}$ & $45.6 \pm 1.2$ & $49.0 \pm 0.8$ & $48.4 \pm 1.1$ & $54.9 \pm 0.9$ & $54.7 \pm 1.0$ & $64.0 \pm 0.9$ & $48.9 \pm 1.3$ & $28.3 \pm 1.7$ & $-{ }^{b}$ \\
\hline L. entomophila & $44.5 \pm 0.8$ & $57.5 \pm 0.4$ & $67.3 \pm 0.7$ & $88.0 \pm 0.2$ & $80.6 \pm 0.5$ & $75.5 \pm 1.3$ & $58.4 \pm 1.3$ & $-b$ & $-{ }^{b}$ \\
\hline L. paeta $^{\mathrm{d}}$ & $-b$ & $36.3 \pm 0.1$ & $65.1 \pm 0.0$ & $59.5 \pm 0.0$ & $59.9 \pm 0.1$ & $69.4 \pm 0.1$ & $60.3 \pm 0.1$ & $44.6 \pm 0.0$ & $-b$ \\
\hline
\end{tabular}


Supplemental Material: Annu. Rev. Entomol. 2014. 59:279-97 doi: 10.1146/annurev-ento-011613-161947

Biology and Management of Psocids Infesting Stored Products Nayak et al.

\begin{tabular}{|c|c|c|c|c|c|c|c|c|c|}
\hline L. reticulatus ${ }^{\mathrm{h}}$ & $-{ }^{c}$ & $46.7 \pm 11.9$ & $40.0 \pm 4.0$ & $40.0 \pm 2.5$ & $46.0 \pm 9.5$ & $33.3 \pm 6.6$ & $8.7 \pm 4.7$ & $-{ }^{c}$ & $-{ }^{c}$ \\
\hline L. rufa ${ }^{c}$ & $-{ }^{b}$ & $76 \pm 3$ & $90 \pm 1$ & $86 \pm 3$ & $91 \pm 3$ & $88 \pm 4$ & $78 \pm 2$ & $82 \pm 4$ & $34 \pm 8$ \\
\hline L. yunnaniensis ${ }^{a}$ & $94.4 \pm 3.0$ & $50.5 \pm 1.5$ & $59.9 \pm 6.6$ & $59.7 \pm 7.6$ & $48.8 \pm 4.3$ & $53.3 \pm 6.3$ & $46.7 \pm 3.2$ & $51.5 \pm 9.6$ & $-{ }^{b}$ \\
\hline \multicolumn{10}{|l|}{ Egg to Adult } \\
\hline L. badia ${ }^{g}$ & $19.8 \pm 2.0$ & $27.1 \pm 5.9$ & $43.5 \pm 2.3$ & $48.3 \pm 3.1$ & $28.0 \pm 5.4$ & $30.5 \pm 0.0$ & $18.0 \pm 2.1$ & $-{ }^{b}$ & $-{ }^{c}$ \\
\hline L. bostrychophila & $37.4 \pm 1.2$ & $52.6 \pm 1.9$ & $60.6 \pm 1.2$ & $82.9 \pm 0.9$ & $81.1 \pm 1.0$ & $62.4 \pm 0.7$ & $50.7 \pm 1.1$ & $-{ }^{b}$ & $-{ }^{b}$ \\
\hline L. decolor ${ }^{f}$ & $38.4 \pm 0.8$ & $42.4 \pm 0.4$ & $43.1 \pm 0.8$ & $49.7 \pm 1.1$ & $51.2 \pm 1.2$ & $57.3 \pm 0.8$ & $40.4 \pm 0.8$ & $19.0 \pm 1.5$ & $-{ }^{b}$ \\
\hline L. entomophila & $32.1 \pm 0.3$ & $45.4 \pm 0.6$ & $53.4 \pm 0.4$ & $64.5 \pm 0.6$ & $59.1 \pm 0.2$ & $51.2 \pm 0.2$ & $37.0 \pm 0.8$ & $-{ }^{b}$ & $-{ }^{b}$ \\
\hline L. paeta ${ }^{d}$ & $-{ }^{b}$ & $18.8 \pm 0.0$ & $45.1 \pm 0.0$ & $40.5 \pm 0.0$ & $36.3 \pm 0.1$ & $52.8 \pm 0.0$ & $34.1 \pm 0.1$ & $28.8 \pm 0.0$ & $-{ }^{b}$ \\
\hline L. yunnaniensis ${ }^{\mathrm{a}}$ & $56.6 \pm 6.2$ & $34.9 \pm 2.4$ & $46.8 \pm 3.6$ & $37.7 \pm 5.1$ & $31.3 \pm 3.1$ & $30.8 \pm 4.4$ & $33.2 \pm 3.6$ & $38.6 \pm 5.6$ & $-{ }^{b}$ \\
\hline
\end{tabular}

Temperature had no effect on egg or nymphal survivorship of L. pearmani. Survivorship of eggs averaged 0.87 (range 0.83 to 0.90 ) and nymphal survivorship averaged 0.52 (range 0.42 to 0.59 ) across all temperatures (Aminatou et al. 2011, refer to Supplemental Table 1). 63-73\% of nymphal mortality occurred during the first and second instars.

Temperature had no effect on egg survivorship of L. rufa. Survivorship of eggs averaged 0.90 (range 0.85 to 0.95 ) across all temperatures (Gautam et al. 2010, refer to Supplemental Table 1).

Temperature had no effect on egg survivorship of L. brunnea. Survivorship of eggs averaged 0.8 (range 0.7 to 1.0 ) across all temperatures (Opit and Throne 2009, refer to Supplemental Table 1). $87-100 \%$ of nymphal mortality occurred during the first and second instars. 
Biology and Management of Psocids Infesting Stored Products

Nayak et al.

Temperatures between 22.5 and $35^{\circ} \mathrm{C}$ had no effect on egg survivorship of L. reticulatus. Survivorship of eggs ranged between 0.8 and 0.9 across all temperatures (Opit and Throne 2008, refer to Supplemental Table 1). No eggs hatched at $40^{\circ} \mathrm{C} .80-100 \%$ of the total nymphal mortality was due to N1 and N2 mortality.

${ }^{a}$ Most mortality occurred in the first stadium (Hassan et al. 2011, refer to Supplemental Table 1).

${ }^{\mathrm{b}}$ This temperature not tested.

${ }^{c} 58-71 \%$ of total nymphal mortality was due to N1 and N2 mortality (Gautam et al. 2010, refer to Supplemental Table 1).

${ }^{\mathrm{d} S}$ Survivorship on a diet of whole wheat flour, skim milk, and yeast powder (10:1:1) (Wang et al. 2009, refer to Supplemental Table 1).

eSurvivorship on cracked wheat (Opit and Throne 2009, refer to Supplemental Table 1). Data in table were read from graph in published study.

fSurvivorship on a diet of whole wheat flour, skim milk, and yeast powder (10:1:1) (Tang et al. 2008, refer to Supplemental Table 1).

${ }^{\text {g} S u r v i v o r s h i p ~ o n ~ a ~ d i e t ~ o f ~ w h o l e ~ w h e a t ~ f l o u r, ~ s k i m ~ m i l k, ~ a n d ~ y e a s t ~ p o w d e r ~(10: 1: 1) ~(J i a n g ~ e t ~ a l . ~ 2008, ~ r e f e r ~ t o ~ S u p p l e m e n t a l ~ T a b l e ~ 1) . ~}$

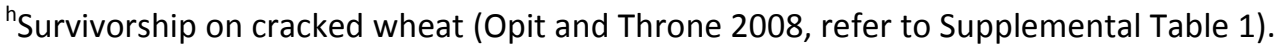

'Survivorship on a diet of whole wheat flour, skim milk, and yeast powder (10:1:1) (Wang et al. 2000, refer to Supplemental Table 1).

${ }^{\mathrm{j} S}$ Survivorship on a diet of whole wheat flour and yeast powder (10:1) (Wang et al. 1998, refer to Supplemental Table 1). Survivorship of eggs at $17.5^{\circ} \mathrm{C}$ and $75 \% \mathrm{RH}$ was $45.4 \pm 1.4 \%$, and was $64.9 \pm 0.3,68.6 \pm 0.7,78.9 \pm 1.2$, and $73.0 \pm 1.1 \%$ at $28^{\circ} \mathrm{C}$ and $60,70,80$, and $90 \% \mathrm{RH}$, respectively. Survivorship of nymphs was $47.9 \pm 2.9,79.5 \pm 1.0,85.9 \pm 1.5$, and $85.6 \pm 1.1 \%$ at $28^{\circ} \mathrm{C}$ and $60,70,80$, and $90 \% \mathrm{RH}$, respectively, and survivorship from egg to adult was 31.2 $\pm 1.8,54.5 \pm 0.4,67.8 \pm 0.2$, and $62.5 \pm 0.4 \%$ at $28^{\circ} \mathrm{C}$ and $60,70,80$, and $90 \% \mathrm{RH}$, respectively. 
Supplemental Material: Annu. Rev. Entomol. 2014. 59:279-97

doi: 10.1146/annurev-ento-011613-161947

Biology and Management of Psocids Infesting Stored Products

Nayak et al.

Supplemental Table 4. Effects of temperature on preoviposition period of Liposcelis spp. and Lepinotus reticulatus at 75 to $80 \% \mathrm{RH}$ (over a saturated sodium chloride solution)

\begin{tabular}{|c|c|c|c|c|c|c|c|c|c|}
\hline \multirow[t]{3}{*}{ Species } & \multicolumn{9}{|c|}{ Preoviposition period (days \pm SE) } \\
\hline & \multicolumn{9}{|c|}{ Temperature $\left({ }^{\circ} \mathrm{C}\right)$} \\
\hline & 20 & 22.5 & 25 & 27.5 & 30 & 32.5 & 35 & 37.5 & 40 \\
\hline L. badiaf & $6.4 \pm 0.4$ & $5.4 \pm 0.4$ & $5.0 \pm 0.3$ & $4.7 \pm 0.4$ & $3.8 \pm 0.6$ & $3.8 \pm 0.4$ & $4.4 \pm 0.3$ & $-{ }^{b}$ & $-b$ \\
\hline L. bostrychophila ${ }^{\mathrm{h}}$ & $17.9 \pm 3.2$ & $10.3 \pm 1.1$ & $4.9 \pm 0.3$ & $3.3 \pm 0.6$ & $3.5 \pm 0.3$ & $4.0 \pm 0.1$ & $4.3 \pm 0.6$ & $-{ }^{b}$ & $-{ }^{b}$ \\
\hline L. decolor ${ }^{e}$ & $6.8 \pm 0.5$ & $5.6 \pm 0.4$ & $4.2 \pm 0.3$ & $4.2 \pm 0.3$ & $3.0 \pm 0.3$ & $2.8 \pm 0.2$ & $2.3 \pm 0.1$ & $3.8 \pm 0.3$ & $-{ }^{b}$ \\
\hline L. paeta $^{d}$ & $-{ }^{b}$ & $6.3 \pm 0.9$ & $3.4 \pm 0.4$ & $3.2 \pm 0.4$ & $2.0 \pm 0.2$ & $1.3 \pm 0.2$ & $1.1 \pm 0.2$ & $0.8 \pm 0.1$ & $-{ }^{b}$ \\
\hline L. reticulatus ${ }^{\mathrm{C}}$ & $-{ }^{b}$ & $4.4 \pm 0.3$ & $4.4 \pm 0.3$ & $3.6 \pm 0.2$ & $3.3 \pm 0.2$ & $2.8 \pm 0.2$ & $2.7 \pm 0.2$ & $-{ }^{b}$ & $-{ }^{b}$ \\
\hline L. rufa ${ }^{i}$ & $-{ }^{b}$ & $4.4 \pm 0.2$ & $2.5 \pm 0.2$ & $1.5 \pm 0.2$ & $1.0 \pm 0.2$ & $1.1 \pm 0.2$ & $0.9 \pm 0.2$ & $2.2 \pm 0.2$ & $2.0 \pm 0.2$ \\
\hline L. tricolor & 50.0 & 66.7 & 14.3 & 8.3 & 3.5 & 5.9 & 6.3 & $-{ }^{b}$ & $-{ }^{b}$ \\
\hline L. yunnaniensis ${ }^{\mathrm{a}}$ & $16.3 \pm 0.2$ & $18.5 \pm 1.5$ & $10.3 \pm 0.6$ & $16.3 \pm 1.0$ & $9.6 \pm 1.1$ & $11.8 \pm 1.1$ & $3.1 \pm 0.5$ & $4.9 \pm 1.0$ & $-{ }^{b}$ \\
\hline
\end{tabular}

${ }^{a}$ Days on a diet of whole wheat flour, skim milk, and yeast powder (10:1:1) (Hassan et al. 2011, refer to Supplemental Table 1).

${ }^{\mathrm{b}}$ This temperature not tested.

'Days on cracked wheat and colored diet containing rice krispies and red dye (Opit GP, Throne JE, Payton ME. 1010. Reproductive parameters of the parthenogenetic psocid Lepinotus reticulatus (Psocoptera: Trogiidae) at constant temperatures. Environ. Entomol. 39:1004-1011) 
Supplemental Material: Annu. Rev. Entomol. 2014. 59:279-97

doi: 10.1146/annurev-ento-011613-161947

Biology and Management of Psocids Infesting Stored Products

Nayak et al.

${ }^{\mathrm{d}}$ Days on a diet of whole wheat flour, skim milk, and yeast powder (10:1:1) (Wang et al. 2009, refer to Supplemental Table 1).

${ }^{\text {e}}$ Days on a diet of whole wheat flour, skim milk, and yeast powder (10:1:1) (Tang et al. 2008, refer to Supplemental Table 1).

fDays on a diet of whole wheat flour, skim milk, and yeast powder (10:1:1) (Jiang et al. 2008, refer to Supplemental Table 1).

${ }^{\text {g}}$ Days (estimated from graph in manuscript) on a diet of whole wheat flour, skim milk, and yeast powder (10:1:1) (Dong et al. 2007, refer to Supplemental Table 1).

${ }^{\mathrm{h}}$ Days on a diet of whole wheat flour, skim milk, and yeast powder (10:1:1) (Wang et al. 2000, refer to Supplemental Table 1).

'Days on cracked hard red winter wheat, rice krispies, and wheat germ (93:5:2) (Gautam SG, Opit GP, Giles KL. 2012. Effects of constant temperatures on reproductive parameters of the psocid Liposcelis rufa (Psocoptera: Liposcelididae). Entomol. Ornithol. Herpetol. S1:002). 
Supplemental Material: Annu. Rev. Entomol. 2014. 59:279-97

doi: 10.1146/annurev-ento-011613-161947

Biology and Management of Psocids Infesting Stored Products

Nayak et al.

Supplemental Table 5. Effects of temperature on oviposition period of Liposcelis spp. and Lepinotus reticulatus at 75 to $80 \%$ RH (over a saturated sodium chloride solution)

\begin{tabular}{|c|c|c|c|c|c|c|c|c|c|}
\hline \multirow{3}{*}{ Species } & \multicolumn{9}{|c|}{ Oviposition period (days \pm SE) } \\
\hline & \multicolumn{9}{|c|}{ Temperature $\left({ }^{\circ} \mathrm{C}\right)$} \\
\hline & 20 & 22.5 & 25 & 27.5 & 30 & 32.5 & 35 & 37.5 & 40 \\
\hline L. badia ${ }^{f}$ & $69.8 \pm 10.6$ & $55.1 \pm 5.6$ & $49.8 \pm 5.7$ & $20.3 \pm 1.9$ & $29.6 \pm 4.2$ & $26.1 \pm 3.6$ & $12.8 \pm 1.1$ & $-b$ & $-\mathrm{b}$ \\
\hline L. decolor ${ }^{e}$ & $85.0 \pm 8.4$ & $61.4 \pm 7.0$ & $60.8 \pm 4.2$ & $49.6 \pm 3.6$ & $41.4 \pm 4.1$ & $51.4 \pm 3.0$ & $37.0 \pm 3.1$ & $17.8 \pm 2.1$ & $-\mathrm{b}$ \\
\hline L. paeta $^{d}$ & $-b$ & $101.8 \pm 9.7$ & $100.7 \pm 4.8$ & $75.0 \pm 4.9$ & $76.2 \pm 5.2$ & $50.9 \pm 3.8$ & $60.7 \pm 3.2$ & $20.3 \pm 0.9$ & $-b$ \\
\hline L. reticulatus ${ }^{\mathrm{c}}$ & $-{ }^{b}$ & $65.5 \pm 2.3$ & $48.8 \pm 2.3$ & $40.6 \pm 2.1$ & $33.2 \pm 2.2$ & $30.9 \pm 2.2$ & $18.4 \pm 2.1$ & $-{ }^{b}$ & $-{ }^{b}$ \\
\hline L. rufa ${ }^{\mathrm{g}}$ & $-b$ & $144.7 \pm 4.9$ & $108.1 \pm 4.9$ & $89.7 \pm 5.1$ & $66.6 \pm 4.8$ & $45.2 \pm 4.8$ & $40.9 \pm 4.8$ & $29.8 \pm 5.0$ & $26.2 \pm 4.9$ \\
\hline L. yunnaniensis ${ }^{\mathrm{a}}$ & $75.1 \pm 8.7$ & $37.0 \pm 4.9$ & $60.1 \pm 3.9$ & $45.2 \pm 4.2$ & $33.4 \pm 3.0$ & $38.9 \pm 3.1$ & $34.1 \pm 2.4$ & $21.6 \pm 2.4$ & $-b$ \\
\hline
\end{tabular}

${ }^{a}$ Days on a diet of whole wheat flour, skim milk, and yeast powder (10:1:1) (Hassan et al. 2011, refer to Supplemental Table 1).

${ }^{\mathrm{b}}$ This temperature not tested.

'Days on cracked wheat and colored diet containing rice krispies and red dye (Opit et al. 2010, refer to Supplemental Table 1).

${ }^{d}$ Days on a diet of whole wheat flour, skim milk, and yeast powder (10:1:1) (Wang et al. 2009, refer to Supplemental Table 1).

${ }^{e}$ Days on a diet of whole wheat flour, skim milk, and yeast powder (10:1:1) (Tang et al. 2008, refer to Supplemental Table 1). 
Supplemental Material: Annu. Rev. Entomol. 2014. 59:279-97

doi: 10.1146/annurev-ento-011613-161947

Biology and Management of Psocids Infesting Stored Products

Nayak et al.

fDays on a diet of whole wheat flour, skim milk, and yeast powder (10:1:1) (Jiang et al. 2008, refer to Supplemental Table 1).

${ }^{8}$ Days on cracked hard red winter wheat, rice krispies, and wheat germ (93:5:2) (Gautam et al. 2012, refer to Supplemental Table 4). 
Supplemental Material: Annu. Rev. Entomol. 2014. 59:279-97

doi: 10.1146/annurev-ento-011613-161947

Biology and Management of Psocids Infesting Stored Products

Nayak et al.

Supplemental Table 6. Effects of temperature on adult longevity of Liposcelis spp. and Lepinotus reticulatus at 75 to $80 \%$ RH (over a saturated sodium chloride solution)

\begin{tabular}{|c|c|c|c|c|c|c|c|c|c|}
\hline \multirow{3}{*}{ Species } & \multicolumn{9}{|c|}{ Adult longevity (days \pm SE) } \\
\hline & \multicolumn{9}{|c|}{ Temperature $\left({ }^{\circ} \mathrm{C}\right)$} \\
\hline & 20 & 22.5 & 25 & 27.5 & 30 & 32.5 & 35 & 37.5 & 40 \\
\hline L. badia $^{f}$ & $76.9 \pm 9.9$ & $63.8 \pm 5.7$ & $59.6 \pm 6.0$ & $29.8 \pm 2.0$ & $41.2 \pm 4.3$ & $35.2 \pm 3.7$ & $20.7 \pm 1.3$ & $-b$ & $-b$ \\
\hline L. bostrychophilag & $80.4 \pm 10.2$ & $82.1 \pm 5.7$ & $85.2 \pm 4.7$ & $86.4 \pm 4.0$ & $89.4 \pm 3.9$ & $78.8 \pm 4.1$ & $60.1 \pm 7.1$ & $-b$ & $-b$ \\
\hline L. decolor ${ }^{e}$ & $101.5 \pm 8.5$ & $77.4 \pm 7.5$ & $70.5 \pm 4.3$ & $58.1 \pm 3.5$ & $52.6 \pm 4.2$ & $56.8 \pm 3.3$ & $42.3 \pm 3.3$ & $26.8 \pm 2.3$ & $-b$ \\
\hline L. entomophila $^{\mathrm{h}}$ & $64.4 \pm 2.9$ & $55.4 \pm 0.5$ & $54.2 \pm 0.4$ & $53.4 \pm 0.1$ & $45.7 \pm 0.2$ & $37.5 \pm 0.4$ & $32.4 \pm 1.2$ & $-{ }^{b}$ & $-b$ \\
\hline L. paeta ${ }^{d}$ & $-b$ & $110.3 \pm 9.6$ & $106.8 \pm 4.7$ & $82.6 \pm 5.0$ & $81.2 \pm 5.5$ & $55.5 \pm 3.8$ & $66.0 \pm 3.3$ & $24.9 \pm 0.7$ & $-b$ \\
\hline L. reticulatus females ${ }^{c}$ & $-b$ & $82.9 \pm 2.3$ & $61.6 \pm 2.4$ & $48.7 \pm 2.2$ & $39.4 \pm 2.2$ & $35.6 \pm 2.3$ & $23.8 \pm 2.2$ & $-b$ & $-b$ \\
\hline L. rufa ${ }^{i}$ & $-b$ & $228.9 \pm 6.1$ & $169.8 \pm 6.1$ & $121.2 \pm 6.3$ & $87.4 \pm 6.1$ & $55.7 \pm 6.0$ & $52.0 \pm 5.9$ & $38.2 \pm 6.3$ & $36.4 \pm 6.2$ \\
\hline $\begin{array}{l}\text { L. yunnaniensis } \\
\text { females }^{a}\end{array}$ & $134.1 \pm 9.5$ & $80.0 \pm 4.5$ & $98.1 \pm 3.9$ & $74.5 \pm 4.1$ & $60.9 \pm 3.8$ & $57.5 \pm 3.5$ & $50.4 \pm 1.6$ & $39.4 \pm 1.8$ & $-b$ \\
\hline
\end{tabular}

${ }^{\mathrm{a}}$ Days on a diet of whole wheat flour, skim milk, and yeast powder (10:1:1) (Hassan et al. 2011, refer to Supplemental Table 1).

${ }^{\mathrm{b}}$ This temperature not tested.

${ }^{c}$ Days on cracked wheat and colored diet containing rice krispies and red dye (Opit et al. 2010, refer to Supplemental Table 4).

${ }^{d}$ Days on a diet of whole wheat flour, skim milk, and yeast powder (10:1:1) (Wang et al. 2009, refer to Supplemental Table 1). 
Supplemental Material: Annu. Rev. Entomol. 2014. 59:279-97

doi: 10.1146/annurev-ento-011613-161947

Biology and Management of Psocids Infesting Stored Products

Nayak et al.

${ }^{\mathrm{e}}$ Days on a diet of whole wheat flour, skim milk, and yeast powder (10:1:1) (Tang et al. 2008, refer to Supplemental Table 1).

fDays on a diet of whole wheat flour, skim milk, and yeast powder (10:1:1) (Jiang et al. 2008, refer to Supplemental Table 1).

${ }^{\mathrm{g}}$ Days on a diet of whole wheat flour, skim milk, and yeast powder (10:1:1) (Wang et al. 2000, refer to Supplemental Table 1).

${ }^{h}$ Days on a diet of whole wheat flour and yeast powder (10:1) (Wang et al. 1998, refer to Supplemental Table 1).

'Days on cracked hard red winter wheat, rice krispies, and wheat germ (93:5:2) (Gautam et al. 2012, refer to Supplemental Table 4). 
Supplemental Material: Annu. Rev. Entomol. 2014. 59:279-97

doi: 10.1146/annurev-ento-011613-161947

Biology and Management of Psocids Infesting Stored Products

Nayak et al.

Supplemental Table 7. Effects of temperature on fecundity of Liposcelis spp. and Lepinotus reticulatus at 75 to $80 \%$ RH (over a saturated sodium chloride solution)

\begin{tabular}{|c|c|c|c|c|c|c|c|c|c|}
\hline \multirow{3}{*}{ Species } & \multicolumn{9}{|c|}{ Fecundity (number of eggs laid during lifetime $\pm S E$ ) } \\
\hline & \multicolumn{9}{|c|}{ Temperature $\left({ }^{\circ} \mathrm{C}\right)$} \\
\hline & 20 & 22.5 & 25 & 27.5 & 30 & 32.5 & 35 & 37.5 & 40 \\
\hline L. badia $^{f}$ & $52.4 \pm 7.3$ & $40.7 \pm 4.6$ & $33.4 \pm 3.7$ & $18.7 \pm 1.6$ & $30.4 \pm 3.1$ & $18.1 \pm 2.1$ & $14.6 \pm 1.4$ & $-\mathrm{b}$ & $-\mathrm{b}$ \\
\hline L. bostrychophila & $51.9 \pm 9.4$ & $55.4 \pm 8.0$ & $64.6 \pm 7.2$ & $74.7 \pm 3.3$ & $74.6 \pm 3.0$ & $64.9 \pm 4.4$ & $61.0 \pm 7.1$ & $-b$ & $-b$ \\
\hline L. decolor ${ }^{e}$ & $65.1 \pm 6.9$ & $68.5 \pm 8.1$ & $87.8 \pm 4.4$ & $91.1 \pm 6.1$ & $107.5 \pm 8.1$ & $130.4 \pm 7.2$ & $74.3 \pm 5.6$ & $24.7 \pm 4.0$ & $-b$ \\
\hline L. paeta ${ }^{d}$ & $-\mathrm{b}$ & $50.5 \pm 5.6$ & $72.7 \pm 5.4$ & $107.6 \pm 7.1$ & $103.8 \pm 8.1$ & $98.5 \pm 8.4$ & $102.1 \pm 7.3$ & $20.5 \pm 1.8$ & $-\mathrm{b}$ \\
\hline L. reticulatus ${ }^{c}$ & $-\mathrm{b}$ & $31.7 \pm 2.1$ & $38.9 \pm 2.1$ & $40.7 \pm 2.0$ & $36.4 \pm 2.0$ & $39.2 \pm 2.0$ & $21.3 \pm 2.0$ & $-\mathrm{b}$ & $-\mathrm{b}$ \\
\hline L. rufa ${ }^{h}$ & $-\mathrm{b}$ & $34.5 \pm 3.0$ & $44.5 \pm 3.0$ & $54.6 \pm 3.1$ & $62.5 \pm 3.2$ & $58.7 \pm 3.0$ & $54.1 \pm 2.9$ & $44.4 \pm 3.1$ & $27.9 \pm 3.1$ \\
\hline L. yunnaniensis ${ }^{a}$ & $13.8 \pm 1.3$ & $10.3 \pm 1.9$ & $27.0 \pm 2.2$ & $24.5 \pm 2.4$ & $21.9 \pm 2.1$ & $29.7 \pm 2.8$ & $32.6 \pm 2.7$ & $12.5 \pm 2.1$ & $-b$ \\
\hline
\end{tabular}

${ }^{a}$ Eggs (Hassan et al. 2011, refer to Supplemental Table 1).

${ }^{\mathrm{b}}$ This temperature not tested.

${ }^{c}$ Eggs on cracked wheat and colored diet containing rice krispies and red dye (Opit et al. 2010, refer to Supplemental Table 4).

${ }^{d}$ Eggs on a diet of whole wheat flour, skim milk, and yeast powder (10:1:1) (Wang et al. 2009, refer to Supplemental Table 1). 
Supplemental Material: Annu. Rev. Entomol. 2014. 59:279-97

doi: 10.1146/annurev-ento-011613-161947

Biology and Management of Psocids Infesting Stored Products

Nayak et al.

${ }^{\mathrm{e}}$ Eggs on a diet of whole wheat flour, skim milk, and yeast powder (10:1:1) (Tang et al. 2008, refer to Supplemental Table 1).

fEggs on a diet of whole wheat flour, skim milk, and yeast powder (10:1:1) (Jiang et al. 2008, refer to Supplemental Table 1).

${ }^{\mathrm{g}}$ Eggs on a diet of whole wheat flour, skim milk, and yeast powder (10:1:1) (Wang et al. 2000, refer to Supplemental Table 1 ). No eggs were laid at $17.5^{\circ} \mathrm{C}$.

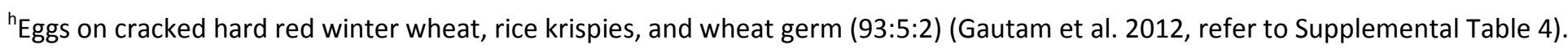


Supplemental Material: Annu. Rev. Entomol. 2014. 59:279-97

doi: 10.1146/annurev-ento-011613-161947

Biology and Management of Psocids Infesting Stored Products

Nayak et al.

Supplemental Table 8. Effects of temperature and relative humidity on population growth of Liposcelis spp. and Lepinotus reticulatus

\begin{tabular}{|c|c|c|c|c|c|c|c|c|}
\hline \multirow{3}{*}{ RH/species } & \multicolumn{8}{|c|}{ Number of psocids ( \pm SE) } \\
\hline & \multicolumn{8}{|c|}{ Temperature $\left({ }^{\circ} \mathrm{C}\right)$} \\
\hline & \multirow[t]{2}{*}{22.5} & \multirow[t]{2}{*}{25} & \multirow[t]{2}{*}{27.5} & \multirow[t]{2}{*}{30} & \multirow[t]{2}{*}{32.5} & \multirow[t]{2}{*}{35} & \multirow[t]{2}{*}{37.5} & \multirow[t]{2}{*}{40} \\
\hline $80 \%$ & & & & & & & & \\
\hline L. bostrychophila ${ }^{f}$ & $34.6 \pm 2.9$ & $158.3 \pm 7.7$ & $682.4 \pm 61.0$ & $3505.2 \pm 238.3$ & $1910.8 \pm 96.7$ & $14.1 \pm 4.3$ & $-{ }^{d}$ & $--^{d}$ \\
\hline L. entomophila ${ }^{f}$ & $31.5 \pm 4.8$ & $77.0 \pm 9.9$ & $169.8 \pm 53.7$ & $333.2 \pm 30.4$ & $167.0 \pm 56.7$ & $0.0 \pm 0.0$ & $-{ }^{d}$ & $-{ }^{d}$ \\
\hline L. paeta ${ }^{f}$ & $4.5 \pm 0.5$ & $69.0 \pm 6.1$ & $249.9 \pm 11.4$ & $501.5 \pm 42.6$ & $717.9 \pm 60.2$ & $837.8 \pm 60.0$ & $374.9 \pm 32.1$ & $-{ }^{d}$ \\
\hline \multicolumn{9}{|l|}{$75 \%$} \\
\hline L. brunnea ${ }^{c}$ & $48.0 \pm 3.4 b$ & $50.4 \pm 4.5$ & $49.9 \pm 4.1$ & $55.0 \pm 4.3$ & $51.7 \pm 3.5$ & $7.7 \pm 2.2$ & $-{ }^{d}$ & $-{ }^{d}$ \\
\hline L. pearmani ${ }^{\mathrm{a}}$ & $39.7 \pm 3.9$ & $79.5 \pm 8.1$ & $97.1 \pm 11.6$ & $120.5 \pm 12.3$ & $161.9 \pm 16.8$ & $69.2 \pm 8.2$ & $0.0 \pm 0.0$ & $0.0 \pm 0.0$ \\
\hline L. reticulatus $^{\mathrm{e}}$ & $46.0 \pm 10.2$ & $50.3 \pm 8.2$ & $55.4 \pm 13.4$ & $94.8 \pm 48.8$ & $102.9 \pm 6.6$ & $4.0 \pm 4.0$ & $-{ }^{d}$ & $-d$ \\
\hline L. rufa & $27.0 \pm 3.6$ & $60.8 \pm 6.8$ & $70.4 \pm 7.7$ & $138.4 \pm 17.5$ & $323.9 \pm 23.4$ & $363.4 \pm 32.9$ & $300.7 \pm 24.5$ & $2.7 \pm 1.3$ \\
\hline \multicolumn{9}{|l|}{$70 \%$} \\
\hline L. bostrychophila ${ }^{f}$ & $30.9 \pm 1.1$ & $112.0 \pm 3.9$ & $204.1 \pm 11.0$ & $3344.0 \pm 244.5$ & $235.1 \pm 63.7$ & $10.7 \pm 3.9$ & $-{ }^{d}$ & $-{ }^{d}$ \\
\hline L. entomophila & $14.7 \pm 3.8$ & $55.8 \pm 12.7$ & $229.0 \pm 72.4$ & $353.4 \pm 26.1$ & $7.9 \pm 7.4$ & $0.0 \pm 0.0$ & $-d$ & $-d$ \\
\hline
\end{tabular}


Supplemental Material: Annu. Rev. Entomol. 2014. 59:279-97 doi: 10.1146/annurev-ento-011613-161947

Biology and Management of Psocids Infesting Stored Products

Nayak et al.

\begin{tabular}{|c|c|c|c|c|c|c|c|c|}
\hline L. paeta ${ }^{f}$ & $4.6 \pm 0.5$ & $89.4 \pm 5.9$ & $306.5 \pm 13.0$ & $963.7 \pm 39.1$ & $1803.5 \pm 111.8$ & $1174.2 \pm 53.7$ & $1092.4 \pm 48.7$ & $-{ }^{d}$ \\
\hline \multicolumn{9}{|l|}{$63 \%$} \\
\hline L. brunnea ${ }^{c}$ & $50.6 \pm 2.8$ & $61.2 \pm 5.6$ & $69.4 \pm 7.0$ & $75.8 \pm 6.9$ & $86.6 \pm 8.2$ & $14.6 \pm 3.2$ & $-{ }^{d}$ & $-d$ \\
\hline L. pearmani & $52.4 \pm 6.9$ & $65.4 \pm 6.9$ & $48.1 \pm 5.0$ & $69.5 \pm 11.2$ & $35.1 \pm 6.4$ & $13.2 \pm 3.6$ & $0.0 \pm 0.0$ & $0.0 \pm 0.0$ \\
\hline L. rufa ${ }^{b}$ & $38.1 \pm 4.0$ & $75.8 \pm 7.3$ & $80.1 \pm 6.3$ & $144.6 \pm 15.8$ & $251.5 \pm 37.0$ & $130.8 \pm 20.1$ & $17.7 \pm 7.6$ & $0.0 \pm 0.0$ \\
\hline \multicolumn{9}{|l|}{$60 \%$} \\
\hline L. bostrychophila ${ }^{f}$ & $18.9 \pm 3.3$ & $48.5 \pm 6.2$ & $62.7 \pm 7.4$ & $9.4 \pm 4.0$ & $0.0 \pm 0.0$ & $0.0 \pm 0.0$ & $-d$ & $-d^{d}$ \\
\hline L. entomophila & $0.1 \pm 0.1$ & $3.2 \pm 2.2$ & $0.0 \pm 0.0$ & $0.0 \pm 0.0$ & $0.3 \pm 0.3$ & $0.0 \pm 0.0$ & $-d$ & $-d$ \\
\hline L. paeta ${ }^{f}$ & $3.0 \pm 0.5$ & $63.5 \pm 4.8$ & $19.8 \pm 6.1$ & $92.9 \pm 40.0$ & $842.3 \pm 135.4$ & $495.0 \pm 120.2$ & $269.0 \pm 59.2$ & $-d$ \\
\hline \multicolumn{9}{|l|}{$55 \%$} \\
\hline L. brunnea ${ }^{c}$ & $44.1 \pm 4.9$ & $43.8 \pm 5.9$ & $57.4 \pm 9.2$ & $58.0 \pm 8.9$ & $27.2 \pm 6.1$ & $2.3 \pm 0.9$ & $-d^{d}$ & $-a^{d}$ \\
\hline L. pearmani $i^{\mathrm{a}}$ & $12.3 \pm 1.3$ & $12.8 \pm 3.5$ & $1.83 \pm 0.8$ & $1.1 \pm 0.5$ & $0.0 \pm 0.0$ & $0.0 \pm 0.0$ & $0.0 \pm 0.0$ & $0.0 \pm 0.0$ \\
\hline L. reticulatus ${ }^{\mathrm{e}}$ & $0.0 \pm 0.0$ & $0.0 \pm 0.0$ & $0.0 \pm 0.0$ & $0.0 \pm 0.0$ & $0.0 \pm 0.0$ & $0.0 \pm 0.0$ & $-d$ & $-{ }^{d}$ \\
\hline L. rufa ${ }^{b}$ & $15.6 \pm 2.0$ & $12.9 \pm 2.3$ & $13.1 \pm 2.0$ & $58.4 \pm 7.0$ & $0.0 \pm 0.0$ & $0.0 \pm 0.0$ & $0.0 \pm 0.0$ & $0.0 \pm 0.0$ \\
\hline \multicolumn{9}{|l|}{$50 \%$} \\
\hline L. bostrychophila & $0.0 \pm 0.0$ & $0.0 \pm 0.0$ & $0.0 \pm 0.0$ & $0.0 \pm 0.0$ & $0.0 \pm 0.0$ & $0.0 \pm 0.0$ & $-{ }^{d}$ & $-d^{d}$ \\
\hline
\end{tabular}


Supplemental Material: Annu. Rev. Entomol. 2014. 59:279-97 doi: 10.1146/annurev-ento-011613-161947

Biology and Management of Psocids Infesting Stored Products

Nayak et al.

\begin{tabular}{|c|c|c|c|c|c|c|c|c|}
\hline L. entomophila ${ }^{f}$ & $0.0 \pm 0.0$ & $0.0 \pm 0.0$ & $0.0 \pm 0.0$ & $0.0 \pm 0.0$ & $0.0 \pm 0.0$ & $0.0 \pm 0.0$ & $-{ }^{d}$ & $-^{d}$ \\
\hline L. paeta $^{f}$ & $0.0 \pm 0.0$ & $0.0 \pm 0.0$ & $0.0 \pm 0.0$ & $0.0 \pm 0.0$ & $0.0 \pm 0.0$ & $0.0 \pm 0.0$ & $-^{d}$ & $-{ }^{d}$ \\
\hline \multicolumn{9}{|l|}{$43 \%$} \\
\hline L. brunnea ${ }^{c}$ & $0.0 \pm 0.0$ & $0.0 \pm 0.0$ & $0.0 \pm 0.0$ & $0.0 \pm 0.0$ & $0.0 \pm 0.0$ & $0.0 \pm 0.0$ & $-^{d}$ & $-^{d}$ \\
\hline L. pearmani $i^{a}$ & $0.0 \pm 0.0$ & $0.0 \pm 0.0$ & $0.0 \pm 0.0$ & $0.0 \pm 0.0$ & $0.0 \pm 0.0$ & $0.0 \pm 0.0$ & $0.0 \pm 0.0$ & $0.0 \pm 0.0$ \\
\hline L. reticulatus ${ }^{\mathrm{e}}$ & $0.0 \pm 0.0$ & $0.0 \pm 0.0$ & $0.0 \pm 0.0$ & $0.0 \pm 0.0$ & $0.0 \pm 0.0$ & $0.0 \pm 0.0$ & $-{ }^{d}$ & $-{ }^{d}$ \\
\hline L. rufa ${ }^{b}$ & $0.0 \pm 0.0$ & $0.0 \pm 0.0$ & $0.0 \pm 0.0$ & $0.0 \pm 0.0$ & $0.0 \pm 0.0$ & $0.0 \pm 0.0$ & $0.0 \pm 0.0$ & $0.0 \pm 0.0$ \\
\hline \multicolumn{9}{|l|}{$40 \%$} \\
\hline L. bostrychophild & $-{ }^{d}$ & $-{ }^{d}$ & $0.0 \pm 0.0$ & $0.0 \pm 0.0$ & $0.0 \pm 0.0$ & $-{ }^{d}$ & $-{ }^{d}$ & $-^{d}$ \\
\hline L. entomophila ${ }^{f}$ & $-{ }^{d}$ & $-{ }^{d}$ & $0.0 \pm 0.0$ & $0.0 \pm 0.0$ & $-{ }^{d}$ & $-^{d}$ & $-{ }^{d}$ & $-{ }^{d}$ \\
\hline L. paeta ${ }^{f}$ & $-{ }^{d}$ & $0.0 \pm 0.0$ & $0.0 \pm 0.0$ & $0.0 \pm 0.0$ & $-{ }^{d}$ & $--^{d}$ & $--^{d}$ & $-{ }^{d}$ \\
\hline \multicolumn{9}{|l|}{$32 \%$} \\
\hline L. reticulatus ${ }^{\mathrm{e}}$ & $0.0 \pm 0.0$ & $0.0 \pm 0.0$ & $0.0 \pm 0.0$ & $0.0 \pm 0.0$ & $0.0 \pm 0.0$ & $0.0 \pm 0.0$ & $-{ }^{d}$ & $-{ }^{d}$ \\
\hline
\end{tabular}

${ }^{a}$ Number of psocids on $5 \mathrm{~g}$ cracked wheat infested with five 1- to 2-wk-old adult females for 30 days (Aminatou et al. 2011, refer to Supplemental Table 1).

${ }^{b}$ Number of psocids on $5 \mathrm{~g}$ cracked wheat infested with five 1- to 2-wk-old adult females for 30 days (Gautam et al. 2010, refer to Supplemental Table 1).

${ }^{c}$ Number of psocids on $5 \mathrm{~g}$ cracked wheat infested with five 1- to 2-wk-old adult females for 30 days (Opit and Throne 2009, refer to Supplemental Table 1). 
Biology and Management of Psocids Infesting Stored Products

Nayak et al.

${ }^{\mathrm{d}}$ This temperature/r.h. combination not tested.

${ }^{\mathrm{e}}$ Number of psocids on $5 \mathrm{~g}$ diet of $97 \%$ cracked hard red winter wheat, $2 \%$ rice krispies, and $1 \%$ brewer's yeast infested with five 1-to 2-wk-old adult females for 46 days (Opit and Throne 2008, refer to Supplemental Table 1).

${ }^{f}$ Number of adult psocids on $5 \mathrm{~g}$ of diet ( $4.25 \mathrm{~g}$ whole brown rice, $0.5 \mathrm{~g}$ ground brown rice, and $0.25 \mathrm{~g}$ fine ground skimmed-milk powder) infested with five adult females and two males (except for $L$. bostrychophila) for 56 days. Actual temperatures tested were $15,18,21,24,27,30,33,36,39$, and 42 . There were $3.8 \pm 0.4,3.1 \pm 0.3$, and $0.0 \mathrm{~L}$. paeta in vials at 15,18 , and $42^{\circ} \mathrm{C}$ and $60 \% \mathrm{RH}$. There were $3.4 \pm 0.3 \mathrm{~L}$. entomophila in vials at $18^{\circ} \mathrm{C}$ and $70 \% \mathrm{RH}$. There were $5.5 \pm 0.4,3.8 \pm 0.3$, and $0.0 \mathrm{~L}$. paeta in vials at 15,18 , and $42^{\circ} \mathrm{C}$ and $70 \% \mathrm{RH}$. There were $3.6 \pm 0.6 \mathrm{~L}$. entomophila in vials at $18^{\circ} \mathrm{C}$ and $80 \% \mathrm{RH}$. There were $6.3 \pm 0.3,4.4 \pm 0.4$, and $252.4 \pm 28.9 \mathrm{~L}$. paeta in vials at 15,18 , and $42^{\circ} \mathrm{C}$ and $80 \% \mathrm{RH}$. (Rees DP, Walker AJ. 1990. The effect of temperature and relative humidity on population growth of three Liposcelis species (Psocoptera: Liposcelidae) infesting stored products in tropical countries. Bull. Entomol. Res. 80:353-58) 